Aus der Abteilung Anaesthesiologie II - Operative Intensivmedizin

(Prof. Dr. med. M. Quintel)

im Zentrum Anaesthesiologie, Rettungs- und Intensivmedizin

der Medizinischen Fakultät der Universität Göttingen

\title{
Der Zusammenhang zwischen dem Erythropoietin-rs1617640-Promotor-Polymorphismus und der Nierenfunktion nach Herzoperationen mit Herz-Lungen-Maschine
}

\author{
INAUGURAL-DISSERTATION \\ zur Erlangung des Doktorgrades \\ der Medizinischen Fakultät \\ der Georg-August-Universität zu Göttingen
}

vorgelegt von

Janna Zimmermann

aus

Braunschweig

Göttingen 2010 
Dekan:

1. Berichterstatter:

2. Berichterstatter/in:

3. Berichterstatter/in:
Prof. Dr. med. C. Frömmel

PD Dr. med. J. Hinz

PD Dr. med. Gross

Prof. Dr. rer. nat. Hilgers

Tag der mündlichen Prüfung: 09.05.2011 


\section{Inhaltsverzeichnis}

Abkürzungsverzeichnis

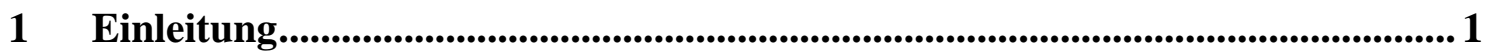

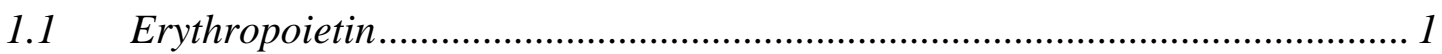

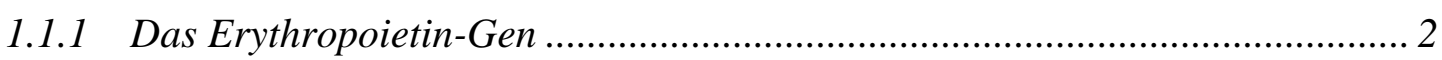

1.1.2 Erythropoietin und Angiogenese ................................................................... 3

1.1.3 Wirkung von Erythropoietin auf die Niere .................................................... 4

1.2 Das akute Nierenversagen (ANV) ...............................................................

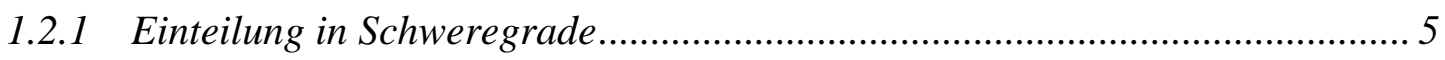

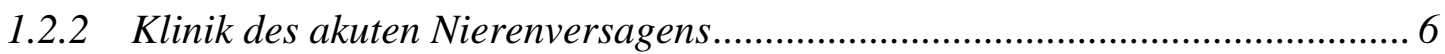

1.2.3 Ursachen des akuten Nierenversagens ........................................................ 6

1.2.4 Therapie des akuten Nierenversagens ........................................................... 7

1.2.5 Akutes Nierenversagen in der Herzchirurgie .................................................. 8

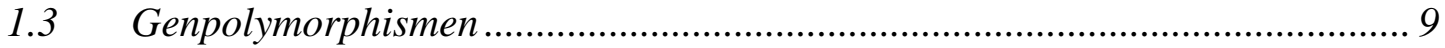

1.3.1 Genpolymorphismen mit Einfluss auf das Herz-Kreislauf- System ................. 11

1.3.2 Genpolymorphismen mit Einfluss auf die Nierenfunktion .............................. 12

1.3.3 Der EPO-SNP-rs1617640-Polymorphismus ................................................ 13

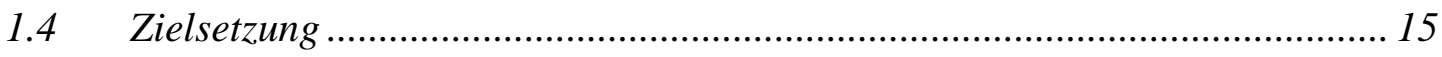

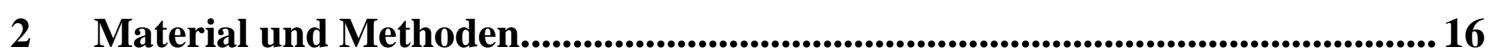

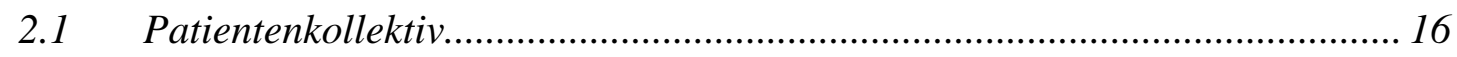

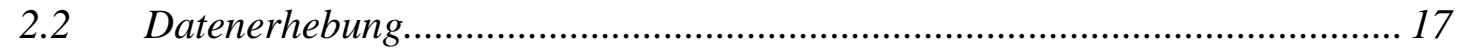

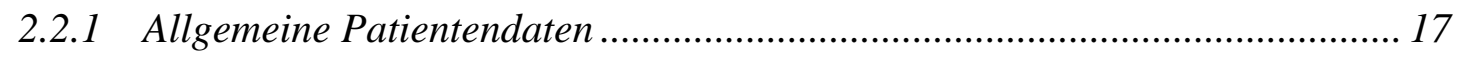

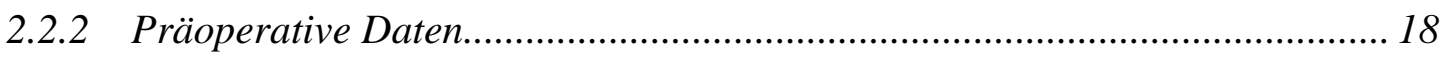

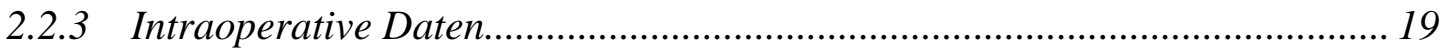

2.2.4 Postoperative intensivmedizinische Überwachung ........................................ 20

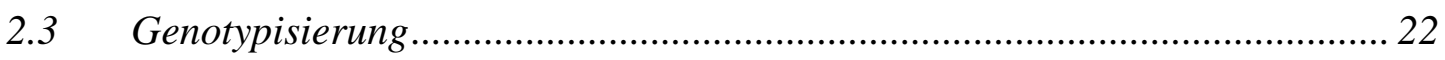

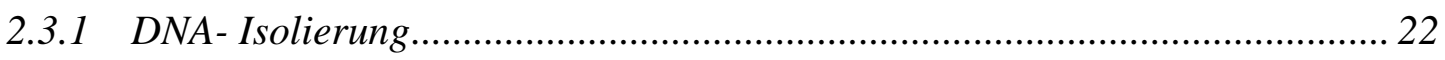

2.3.2 Polymerasekettenreaktion (PCR) ............................................................... 24

2.3.3 Allelische Diskriminierung mittels Real-Time-PCR ...................................... 25

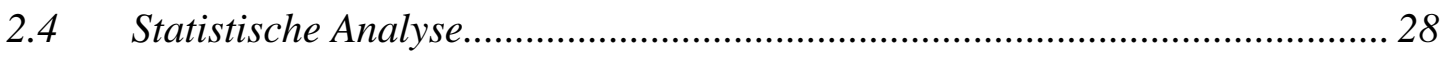




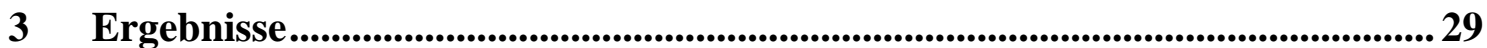

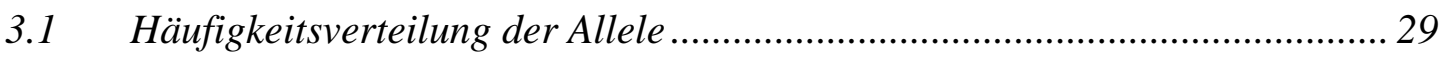

3.2 Vergleich der klinischen und demographischen Daten ................................. 29

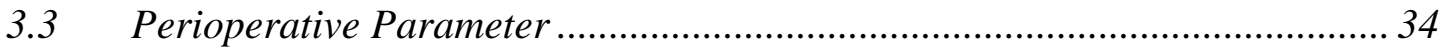

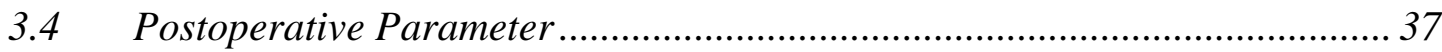

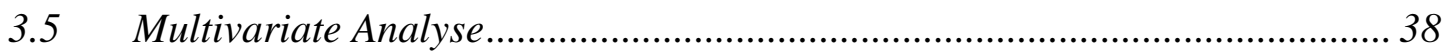

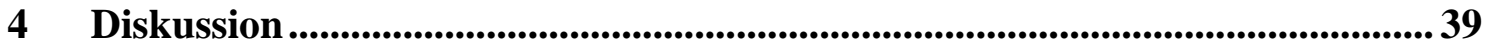

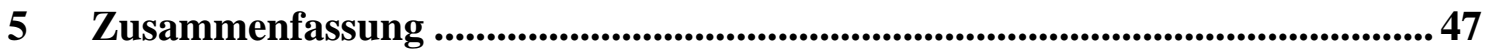

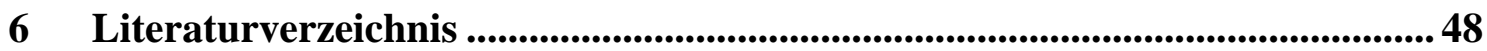

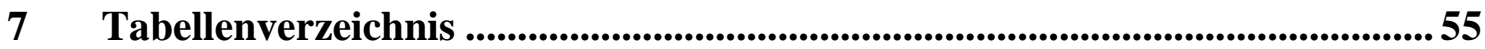




\section{Abkürzungsverzeichnis}

Abb.

ACE

ACVB

$\mathrm{ADH}$

ANV

AP

APACHE

ARDS

ARF-Score

ASD

AT1

AV-Block

BMI

$\mathrm{bp}$

$\mathrm{Ca}^{2+}$

CI

$\mathrm{Cl}$ (Krea)

COPD

CVVH

CSS

DNA

E

ECMO

E-Cup

EDTA

eGFR

EK

EKG

ELWI

eNOS
Abbildung

Angiotensin-Converting-Enzyme

Aorto-Koronarer Venen-Bypass

Antidiuretisches Hormon

Akutes Nierenversagen

Angina pectoris

Acute physiology and chronic health evaluation

Acute respiratory distress syndrome

Acute renal failure Score

Atrio- septaler Defekt

Angiotensin 1

Atrio-ventrikulärer Block

Body Mass Index

Basenpaare

Calcium

Cardiac Index

Kreatinin-Clearance

Chronisch obstruktive Lungenerkrankung

Kontinuierliche veno-venöse Hämofiltration

Canadian Cardiovascular Society

Desoxyribonucleinsäure

End stage kidney disease

Extrakorporale Membranoxygenierung

Eppendorf-Cup

Ethylendiamintetraacetat

Estimated (errechnete) glomeruläre Filtrationsrate

Erythrozytenkonzentrat

Elektrokardiogramm

Extravasaler Lungenwasser-Index

Endotheliale NO-Synthase 


\begin{tabular}{|c|c|}
\hline EPO & Erythropoietin \\
\hline ESF & Erythropoesis stimulating factor \\
\hline ESKD & End stage kidney disease \\
\hline ESRD & End stage renal disease \\
\hline ET1 & Endothelin 1 \\
\hline $\mathrm{F}$ & Failure \\
\hline FRET & Fluoreszenz-Energie-Transfer \\
\hline $\mathrm{G}$ & Guanin \\
\hline GFR & Glomeruläre Filtrationsrate \\
\hline $\mathrm{H}$ & hour \\
\hline $\mathrm{Hb}$ & Hämoglobin \\
\hline $\mathrm{HF}$ & Herzfrequenz \\
\hline HF1 & Hypoxia-inducible-factor 1 \\
\hline Hkt & Hämatokrit \\
\hline HLM & Herz-Lungen-Maschine \\
\hline HOCM & Hypertroph obstruktive Kardiomyopathie \\
\hline $\mathrm{HZV}$ & Herzzeitvolumen \\
\hline I & Injury \\
\hline IABP & Intraaortale Ballonpumpe \\
\hline IL6 & Interleukin 6 \\
\hline ITBV & Intrathorakales Blutvolumen \\
\hline JAK2 & Janus-Kinase 2 \\
\hline $\mathrm{kDa}$ & Kilodalton \\
\hline KHK & Koronare Herzkrankheit \\
\hline $\mathrm{L}$ & Loss of function \\
\hline LAP & Links-atrialer Druck \\
\hline MAP & Mean arterial pressure \\
\hline m-RNA & Messenger-Ribonukleinsäure \\
\hline $\mathrm{N}$ & Stickstoff \\
\hline NO & Stickstoffmonoxid \\
\hline NYHA & New York Heart Association \\
\hline $\mathrm{O}$ & Sauerstoff \\
\hline PAP & Pulmonalarterieller Druck \\
\hline
\end{tabular}


PAVK Periphere arterielle Verschlusskrankheit

PCR Polymerasekettenreaktion

PCWP Pulmonary capillary wedge pressure

PDR Proliferative diabetische Retinopathie

PICCO Pulscontour continuous cardiac output

PPSB Prothrombinkomplex-Konzentrat

PRIND Prolongierte reversible Ischämie mit neurologischem Defizit

PTCA Perkutane Transluminale Koronare Angioplastie

PVRI Pulmonary vascular resistance index

R Risk

RAAS Renin-Angiotensin-Aldosteron-System

rHuEPO Rekombinantes humanes Erythropoietin

rpm Rounds per minute

S-CPK Serum-Kreatinphosphokinase

S-CPK-MB Serum-Kreatinphosphokinase-Muscle Brain

S-Krea Serum-Kreatinin

SAPS Simplified acute physiology score

SD Standardabweichung

SNP Single nucleotide polymorphism

STAT5 Signal transducer and activator of transcription 5

SVI Schlagvolumen-Index

SVRI Systemic vascular resistance index

T Thymin

Tab. Tabelle

TIA Transitorisch ischämische Attacke

U/1 Unit pro Liter

VEGF Vascular endothelial growth factor

VSD Ventrikelseptumdefekt

ZVD Zentralvenöser Druck

ZVK Zentraler Venenkatheter 


\section{$1 \quad$ Einleitung}

\subsection{Erythropoietin}

Erythropoietin (EPO) ist ein 30,4 kDa schweres Glykoprotein, das für die vermehrte Produktion von Hämoglobin (dem für den Sauerstofftransport in roten Blutkörperchen relevanten Bestandteil) verantwortlich ist. Es wurde früher auch als ESF (erythropoesis stimulating factor) bezeichnet oder als Hämatopoietin (Ibelgaufts 1992). Dass Hypoxie ein Stimulans für die vermehrte Produktion der roten Blutzellmasse sein könnte, wurde bereits im Jahr 1882 vermutet. Später nahm man dann an, dass ein humoraler Faktor ursächlich beteiligt sei, den man im Jahr 1946 isolieren konnte und dem man den Namen Erythropoietin gab (Porter und Goldberg 1993).

Pränatal wird EPO hauptsächlich in der Leber gebildet. Nach der Geburt wird die Niere zum Hauptbildungsort dieses Hormons. Der Anteil der EPO-m-RNA, der bei Menschen aus der Leber stammt, ist bislang jedoch unklar. Während er bei Nagetieren bis zu 50\% beträgt, ist anzunehmen, dass der Anteil bei Menschen deutlich geringer ist. Einen Hinweis darauf gibt die Tatsache, dass bei Patienten mit chronischem Nierenversagen der EPO-Spiegel deutlich erniedrigt ist und somit nicht durch die vermehrte Bildung aus anderen EPO-produzierenden Organen (wie z.B. der Leber) kompensiert werden kann (Bondurant und Koury 1986). Auch der Mechanismus, der die pränatale Produktion aus der Leber in die postnatale in der Niere umschalten lässt, ist noch nicht vollständig geklärt.

Über die genannten Organe hinaus konnte eine EPO-Produktion im menschlichen Körper ebenfalls aus Makrophagen (Vogt et al. 1989) und aus bestimmten Tumoren (cerebelläres Hämangiom (Jeffreys et al. 1982), Nierenzellkarzinom (DaSilva et al. 1990) und Hepatom (Okabe et al. 1985)) nachgewiesen werden. Des Weiteren gelang der Nachweis einer EPO-Produktion aus dem Uterus, Endothelzellen, Gefäßmuskelzellen, Insulin-produzierenden Zellen (Chong et al. 2002) und dem Nervensystem (Genc et al. 2004; Anagnostou et al. 1994).

Uneinigkeit herrscht bislang auch über den Erythropoietin-produzierenden Zelltyp in der Niere. So konnten Koury et al. durch immunhistochemische Verfahren und in-situ-Hybridisierung die peritubulären Endothelzellen (Koury et al. 1988) sowie 
die Fibroblasten (Bachmann et al. 1993) des Nierengewebes als Produktionsort von EPO identifizieren. Maxwell et al. hingegen vertraten die Meinung, dass ausschließlich tubuläre Zellen für die EPO-Produktion verantwortlich seien (Maxwell et al. 1990). Der EPO-Rezeptor findet sich auf einer Vielzahl unterschiedlicher Zellen, darunter Zellen des Gehirns, der Retina, des Herzens, der Skelettmuskulatur, der Niere und des Endothels (Digicaylioglu et al. 1995; Juul et al. 1998).

\subsubsection{Das Erythropoietin-Gen}

Das EPO-Gen befindet sich auf dem langen Arm des humanen Chromosoms 7 (Lokalisation 7q21) und ist etwa 3000bp (Basenpaare) lang. Es enthält 5 Exons und 4 Introns. Das Gen kodiert für ein - nach Abtrennung eines 27 Aminosäuren umfassenden N-terminalen Peptides und eines C-terminalen Arginins - 165 Aminosäuren langes Protein (Romanowski und Sytkowski 1994). Erythropoietin enthält 4 glykosilierte Ketten, darunter drei N-gebundene und eine O-gebundene Oligosaccharid-Seitenkette. Diese Ketten sind wichtig für die biologische Aktivität von EPO und schützen das EPOProtein vor Schädigung durch Sauerstoffradikale. Des Weiteren sind die N- und Ogebundenen Ketten notwendig für die Produktion und Sekretion von EPO (Uchida et al. 1997).

Die Kontrolle der EPO-Produktion unterliegt hauptsächlich dem Sauerstoffgehalt des Blutes. Die Blutkonzentration beim Gesunden liegt zwischen 6 und $32 \mathrm{U} / 1$, sie kann sich allerdings unter hypoxämischen Zuständen (z.B. bei chronisch anämischen Patienten) auf den 1000fachen Wert erhöhen (Estler 1999). Die EPOSynthese wird vorwiegend stimuliert durch einen sinkenden $\mathrm{O}_{2}$-Partialdruck bzw. die daraus resultierende Gewebshypoxie. Sie wird durch die Bindung von Proteinen, im Wesentlichen des hypoxia-inducible-factor 1 (HF1) induziert (Jelkmann und Metzen 1996).

Die Regulation der EPO-Synthese geschieht über die Bindung von Proteinen an den Enhancer am Promotor der EPO-Gens. Der Enhancer reagiert auf Hypoxie und führt beim EPO-Gen zu einer bis zu 100fachen Verstärkung der Genexpression (Pugh et al. 1991; Semenza und Wang 1992). Hypoxische Zustände stimulieren die Niere zur Steigerung der EPO-Produktion, welches dann zum Knochenmark zirkuliert. Dort 
bindet es an die EPO-Rezeptoren erythropoietischer Progenitorzellen und verhindert durch Aktivierung bestimmter Signalwege deren Apoptose (Koury und Bondurant 1990). Die Bindung von EPO an den EPO-Rezepter führt zur Dimerisation des Rezeptors, woraufhin das Enzym „Janus-Kinase 2“ (JAK2) den Transkriptionsfaktor „Signal transducer and activator of transcription 5“ (STAT5) phosphoryliert und somit gleichzeitig aktiviert (Juul 2000). Dadurch können die Zellen proliferieren und sich differenzieren. Es wird vermutet, dass auch eine negative Rückkopplung existiert, sodass bei vermehrter Anzahl von Erythrozyten und somit geringerer Hypoxie die EPOProduktion wieder vermindert wird (Huang und Bunn 1995). Des Weiteren wird unter Hypoxie nicht nur die Synthese von EPO gesteigert, sondern außerdem die Expression des EPO-Rezeptors in Leber und Niere erhöht.

\subsubsection{Erythropoietin und Angiogenese}

Jaquet et al. entdeckten 2002, dass Erythropoietin ein deutliches angiogenetisches Potential im Herzmuskelgewebe aufweist. So konnten sie eine 220 \%ige Steigerung der Angiogenese bei Gabe von rekombinantem humanem EPO (rHuEPO) in vitro nachweisen (Jaquet et al. 2002). Außerdem konnte die Stimulation der Angiogenese durch EPO auch in Aortenringen der Ratte (Carlini et al. 1995), der Chorioallantois des Huhnes und dem Endometrium der Maus (Ribatti et al. 1999) nachgewiesen werden sowie in humanen Umbilikalvenen und bovinen adrenalen Kapillaren (Anagnostou et al. 1990).

Für das Verständnis der Wirksamkeit von EPO in Bezug auf die Angiogenese ist es wichtig $\mathrm{zu}$ wissen, dass hämatopoetische und endotheliale Zelllinien einen gemeinsamen Progenitor besitzen, den Hämangioblasten (Tavian et al. 2000) und dass EPO die Proliferation und Differenzierung dieses Hämangioblasten reguliert (Jelkmann 1994). EPO bewirkt an den Endothelzellen verschiedene Effekte: $\mathrm{Ca}^{2+}$-Mobilisierung, Endothelin 1 (ET1)-Synthese und -Freisetzung, Angiogenese, mitogene Effekte, synergistische Wirkungen mit VEGF-Effekten (Juul 2000) sowie Proliferation, Migration und Anti- Apoptose von reifen Endothelzellen (Heeschen et al. 2003). Des Weiteren konnte eine positive Wirkung von EPO auf die Herzfunktion nach Myokardinfarkt gezeigt werden. Es ließ sich eine protektive Wirkung gegenüber 
Zellapoptose, eine verminderte Infarktgröße und im Resultat eine bessere Herzfunktion und Ventrikelkontraktion nachweisen (Parsa et al. 2004).

Erythropoietin wird derzeit in der Medizin zur Behandlung anämischer Zustände bei chronischer Niereninsuffizienz genutzt sowie für anämische Patienten vor einer (nicht-kardiovaskulären) Operation, um den Bedarf an Bluttransfusionen zu verringern. Des Weiteren ist es zur Behandlung von Patienten mit Anämie nach Chemotherapie (bei nicht-myeloischen Krebserkrankungen) und HIV-infizierte Patienten mit medikamentenassoziierter Anämie (v. a. bei Therapie mit Zidovudin) zugelassen (Maiese et al. 2005).

\subsubsection{Wirkung von Erythropoietin auf die Niere}

Bahlmann et al. konnten an Experimenten mit Ratten zeigen, dass eine niedrig dosierte Therapie mit Darbopoietin- $\alpha$ (das länger wirksame hyperglykosilierte Analogon von EPO) die Niere bei chronischem Nierenversagen signifikant verbessern konnte. Dies könnte darauf zurückzuführen sein, dass EPO die Auswirkungen von oxidativem Stress, welcher eine bekannte Ursache für Nierenfunktionsstörungen ist, vermindern kann.

Song et al. demonstrierten 2009 in einer kleinen Pilotstudie, dass die prophylaktische Gabe von EPO ein akutes Nierenversagen nach einer elektiven Bypass-Operation am Herzen verhindern konnte und eine Verbesserung der postoperativen Nierenfunktion zu verzeichnen war. Jedoch ist hierbei zu erwähnen, dass die Anzahl der untersuchten Patienten in dieser Studie nur sehr gering war (Song et al. 2009).

Andererseits wird vermutet, dass EPO in hoher Dosis die Blutviskosität erhöht und somit das potentielle Risiko für Thrombosen steigt. Des Weiteren kann ein Anstieg des Hämatokrits (Hkt) nach EPO-Gabe bei Ratten mit chronischem Nierenversagen einen glomerulären Schaden verstärken und einen Hypertonus induzieren. Es könnte außerdem eine Endothelin-vermittelte Vasokonstriktion der Nierengefäße induzieren und somit die Nierendurchblutung verringern (Ishikawa et al. 1999; Karadag et al. 2009). Auch Corwin et al. konnten in einer Studie im Jahr 2007 demonstrieren, dass bei Patienten mit EPO-Administration im Vergleich zur Kontrollgruppe das Auftreten thrombembolischer Ereignisse signifikant erhöht war (Corwin et al. 2007). 


\subsection{Das akute Nierenversagen (ANV)}

Das akute Nierenversagen ist definiert als eine akut einsetzende, rasche Abnahme der Nierenfunktion, die über Stunden bis Tage anhält und prinzipiell reversibel ist. Das klinische Spektrum reicht von einer minimalen Erhöhung des Serum-Kreatinins (SKrea) bis hin zum vollständigen Verlust der Nierenfunktion. In der Regel geht die eingeschränkte Funktion der Niere einher mit einer Retention harnpflichtiger Substanzen sowie einer Störung des Flüssigkeitshaushaltes, des Elektrolythaushaltes und des Säure-Base-Haushaltes.

Das akute Nierenversagen ist insbesondere auf Intensivstationen mit einer Inzidenz von 5 bis $20 \%$ eine sehr häufige Komplikation. Meist tritt es nicht allein auf, sondern in Kombination mit anderen Organversagen wie z.B. dem ARDS (acute respiratory distress syndrome $=$ Schocklunge) oder dem Kreislaufversagen .

\subsubsection{Einteilung in Schweregrade}

Das akute Nierenversagen kann anhand zweier verschiedener Scores eingeteilt werden, dem RIFLE- und dem AKIN-Score. Die Einteilung der Stadien geschieht nach der Urinmenge/ Tag sowie dem Serum-Kreatinin. Kreatinin ist ein Abbauprodukt des Muskelstoffwechsels und ein indirekter Parameter zur Nierenfunktionsbestimmung, da es im Glomerulus frei filtriert wird und somit bei eingeschränkter Nierenfunktion vermehrt im Serum zurückbleibt. Der Kreatininwert im Blut sollte bei Männern 0,6- 1,1 mg/dl betragen und bei Frauen 0,5- 0,9 mg/dl (Renz-Polster und Krautzig 2008). Die Interpretation des Kreatinin-Wertes setzt voraus, dass eine normal ausgeprägte Muskulatur vorliegt, bei kachektischen oder sehr muskulösen Patienten muss der Normwert angepasst werden.

Eine genauere Aussage über die Nierenfunktion kann allerdings die KreatininClearance geben. Die Kreatinin-Clearance aus dem 24-Stunden-Sammelurin korreliert annähernd mit der glomerulären Filtrationsrate (GFR). 


\subsubsection{Klinik des akuten Nierenversagens}

Beim ANV findet sich im Regelfall ein typischer Verlauf, der sich in vier Phasen einteilen lässt. Die Krankheit beginnt mit der Initialphase oder auch Schädigungsphase, in der ein bestimmtes auslösendes Ereignis auftritt. Die Nierenfunktion ist zu diesem Zeitpunkt noch normal. Es folgt die Phase der manifesten Niereninsuffizienz, die durch eine Oligo- oder Anurie gekennzeichnet ist. In dieser Phase steigen die Retentionswerte an, es zeigen sich Zeichen der Überwässerung wie arterielle Hypertonie, periphere Ödeme oder ein Lungenödem. In der dritten Phase (Erholungsphase) setzt die Urinausscheidung wieder ein, es kommt zu einer Polyurie mit Ausscheidungsmengen von bis zu 10 Liter/Tag, wenn die zuvor geschädigten Tubuluszellen ihre Funktion wieder aufnehmen. Da ihre Fähigkeit zur Konzentrierung des Harns aber noch nicht wieder vollständig wiederhergestellt ist, wird durch hohe Serumharnstoffwerte eine osmotische Diurese ausgelöst. Problematisch für die Patienten in dieser Phase ist die hohe Gefahr der schnellen Austrocknung und des Elektrolytverlustes, auf Grund dessen eine ausreichende Volumensubstitution mit Infusionen hier obligat ist. Die Mortalität in dieser Phase ist mit $25 \%$ sehr hoch. Während der letzten Phase, der Regenerationsphase, normalisiert sich die Diurese und es kommt $\mathrm{zu}$ einer meist vollständigen Erholung der Nierenfunktion (Renz-Polster und Krautzig 2008).

\subsubsection{Ursachen des akuten Nierenversagens}

Bei den Ursachen eines akuten Nierenversagens unterscheidet man drei große Gruppen:

1. prärenale Ursachen $\quad 60 \%$

2. intrarenale Ursachen $\quad 35 \%$

3. postrenale Ursachen $\quad 5 \%$.

Am häufigsten ist die Ursache für ein akutes Nierenversagen prärenal gelegen. Eine verminderte Durchblutung des Nierengewebes bedingt diese Art des Nierenversagens. Für dieses Phänomen kann es verschiedene Auslöser geben. In der Regel führen Blutungen (z.B. nach Unfällen oder Operationen) oder auch eine vermehrte Diurese zu 
einem Volumenmangel, was in der Hypoperfusion der Niere resultiert. Auch eine systemische Vasodilatation, wie sie bei einer Sepsis auftritt, kommt als Ursache in Frage. Es können aber auch lokale Ereignisse auftreten, wie die Konstriktion der Nierenarterie (z.B. Zytokin-vermittelt) oder eine Nierenarterienembolie.

Neben einigen pulmonalen spielen vor allem die kardialen Ursachen eine entscheidende Rolle. Sowohl ein Herzinfarkt als auch Herzrhythmusstörungen können durch ein vermindertes Herzzeitvolumen (HZV) ein prärenales akutes Nierenversagen auslösen. Pathophysiologisch kommt es durch die verminderte Durchblutung der Niere zu einer Aktivierung des Renin-Angiotensin-Aldosteron-Systems (RAAS), welches eine Gefäßkontraktion sowie eine vermehrte Rückresorption von Natrium und Wasser im Tubulussystem der Niere zur Folge hat. Die zusätzliche Ausschüttung von Katecholaminen und ADH unterstützen diese Vorgänge. Es kommt zur Überwässerung des Körpers sowie zu Elektrolytverschiebungen, da die Niere diese nicht mehr effektiv ausscheiden kann.

\subsubsection{Therapie des akuten Nierenversagens}

In der Regel ist eine intensivmedizinische Überwachung des Patienten erforderlich, da es aufgrund von Überwässerung zu einem Lungenödem oder Hirnödem mit komatösen Zuständen kommen kann. Bei eingeschränkter Nierenfunktion kann diese den Wasserund Elektrolythaushalt nicht mehr ausreichend regulieren und es kann in der Folge zu Elektrolytentgleisungen (z.B. Hyperkaliämie) mit lebensbedrohlichen Herzrhythmusstörungen kommen.

Ist das ANV konservativ nicht beherrschbar, sollte eine Nierenersatztherapie (Hämodialyse) durchgeführt werden. So können toxische Substanzen aus dem Körper entfernt werden und der Elektrolyt- sowie der Säure-Basen-Haushalt aufrechterhalten werden. Indikationen für die Hämodialyse sind eine medikamentös nicht beherrschbare Hyperkaliämie, Azidose oder Überwässerung sowie stark erhöhte Retentionswerte (SKrea $>$ 4- $6 \mathrm{mg} / \mathrm{dl}$, Harnstoff $>120-140 \mathrm{mg} / \mathrm{dl}$ ) oder Urämiezeichen (z.B. Übelkeit, Erbrechen oder Juckreiz) 


\subsubsection{Akutes Nierenversagen in der Herzchirurgie}

Das akute Nierenversagen im postoperativen Verlauf nach einer Herzoperation mit Anschluss an die Herz-Lungen-Maschine ist eine gefürchtete und gefährliche Komplikation mit einer beschriebenen Inzidenz zwischen $1 \%$ und $31 \%$ (Mangano et al. 1998; Chertow et al. 1998; Sear 2005). Obwohl schon einige präoperative Risikofaktoren bekannt sind, ist der Einfluss von prä- und intraoperativen Risikofaktoren auf die Entwicklung eines postoperativen Nierenversagens noch immer schlecht verstanden (Conlon et al. 1999). Man nimmt an, dass eine ischämische Schädigung der Niere, resultierend aus einer inadäquaten Perfusion, ein Hauptfaktor für die Entwicklung einer postoperativen Niereninsuffizienz ist. Des Weiteren könnten aber auch Exotoxine (z.B. Antibiotika, Kontrastmittel, Diuretika) oder Endotoxine (z.B. Myoglobin) eine Rolle spielen (Endre 1997). Eine bereits präoperativ bestehende Nierenschädigung, und sei es nur eine gering erhöhte Serumkreatinin-Konzentration ( $>1,2 \mathrm{mg} / \mathrm{dl})$, geht mit einer deutlich erhöhten perioperativen Morbidität und Mortalität einher (Antunes et al. 2004). Ist der Verlauf des Nierenversagens so schwer, dass eine Nierenersatztherapie erforderlich wird, steigt die Mortalitätsrate auf bis zu $63 \%$ (Chertow et al. 1998; Mangano et al. 1998).

Die Dauer des Anschlusses an die Herz-Lungen-Maschine spielt eine weitere bedeutende Rolle bezüglich der postoperativen Nierenfunktion. Eine extrakorporale Zirkulation wie beim Anschluss an die Herz- Lungen- Maschine ist mit einer multiplen Störung der renalen Physiologie und Funktion assoziiert. Diese Pathophysiologie ist erklärbar durch nicht-pulsatilen Blutfluss, makro- und mikroembolische Schädigungen der Niere, Steigerung der zirkulierenden Katecholamine und Entzündungsmediatoren sowie Freisetzung von freiem Hämoglobin aus geschädigten roten Blutzellen. Daher sind bei Anwendung der Herz- Lungen- Maschine erhebliche Verminderungen (25- 75 \%) des renalen Blutflusses und der glomerulären Filtrationsrate zu vermerken, einhergehend mit einem korrespondierenden Anstieg des renalen Gefäßwiderstandes. Dass dieses Phänomen negative Auswirkungen auf die Nierenfunktion zeigt, ist nachvollziehbar (Doggrell 2002). Sofern der Anschluss an die HLM länger als 90 Minuten beträgt, steigt das Risiko für die Entwicklung einer Niereninsuffizienz signifikant an (Taniguchi et al. 2007).

Es ist bekannt, dass das Auftreten eines postoperativen Nierenversagens mit erhöhter Morbidität, längerer Verweildauer im Krankenhaus und höheren Kosten für 
das Gesundheitssystem einhergeht. Mangano und Mitarbeiter führten 1998 eine Studie durch, in der sie 2222 Patienten, die sich einer Herzoperation mit HLM unterzogen, auf ihre postoperative Nierenfunktion untersuchten. Dabei zeigte sich, dass $7,7 \%$ der Patienten eine postoperative Niereninsuffizienz entwickelten; 1,4\% aller Patienten entwickelten ein dialysepflichtiges Nierenversagen. Die Mortalität, die Dauer des Aufenthaltes auf der Intensivstation und die Dauer des Krankenhausaufenthaltes waren signifikant höher bzw. länger bei diesen Patienten im Vergleich zu denen mit normaler postoperativer Nierenfunktion. Des Weiteren war bei einer signifikant größeren Patientenanzahl mit postoperativer Nierenfunktionsstörung im Anschluss an den Krankenhausaufenthalt die Entlassung in eine Langzeitpflege nötig (Mangano et al. 1998).

Auch Chertow et al. zeigten 1998, dass ein Nierenversagen nach Herzoperationen mit Einsatz der HLM mit einer erhöhten frühen Mortalität einhergeht, sogar unter einer frühen und intensiven Therapie.

\subsection{Genpolymorphismen}

Das menschliche Genom besteht aus ca. 3,08 Milliarden Basen, dessen genaue Basenabfolge im Jahr 2003 zu 99,99 \% entschlüsselt war. Von diesen 3,08 Milliarden Basen zählen allerdings nur etwa fünf Prozent $\mathrm{zu}$ den kodierenden Bereichen. Den restlichen 95 Prozent wird bisher eher eine indirekte Funktion bei der Genexpression zugeschrieben. Die DNA enthält vier verschiedene Basen, die zwei Pyrimidine Thymin und Cytosin sowie die zwei Purine Adenin und Guanin. Sie befindet sich im Zellkern in Form eines Chromosoms aufspiralisiert und enthält die gesamte genetische Information eines Menschens.

Jeder Mensch besitzt mutmaßlich 20.000 bis 25.000 Gene. Von einigen dieser Gene sind sogenannte Polymorphismen bekannt. Ein genetischer Polymorphismus ist definiert als die durch Mutationen verursachten Unterschiede in der Nukleotidsequenz homologer Bereiche. Beträgt die Allelfrequenz einer solchen Veränderung mehr als ein Prozent einer Population, so spricht man von einem Polymorphismus. Liegt die Allelfrequenz unterhalb eines Prozents, so wird die Veränderung als seltene genetische Variation bezeichnet. Innerhalb der Polymorphismen lassen sich drei Typen 
unterscheiden: Einzelnukleotid- Polymorphismen, Repeat- Polymorphismen sowie Insertions-/ Deletions-Polymorphismen.

Mit etwa $90 \%$ aller genetischen Variationen sind die EinzelnukleotidPolymorphismen (SNPs = single nucleotide polymorphisms) die häufigste Ursache für Genpolymorphismen. Hierbei handelt es sich um Variationen einzelner Basenpaare in einem DNA-Strang, sogenannten Punktmutationen. Man unterscheidet zwischen Transversionen (eine Purinbase wird durch eine Pyrimidinbase ersetzt oder umgekehrt) und Transitionen (eine Pyrimidinbase wird durch eine Pyrimidinbase oder eine Purinbase durch eine Purinbase ersetzt, d.h. Thymin $\leftrightarrow$ Cytosin oder Adenin $\leftrightarrow$ Guanin). Während diese Mutationen zumeist in einem veränderten oder nicht funktionstüchtigen Protein resultieren, gibt es allerdings auch Mutationen, die überhaupt keine Veränderung eines Proteins nach sich ziehen (so genannte stille Mutationen). Repeat-Polymorphismen bestehen aus Wiederholungen eines Basentripletts (z.B. CAG bei der Chorea Huntington). Solche Wiederholungen kommen auch physiologisch vor, lassen jedoch ab einer bestimmten Anzahl der „Repeats“ meist auf Pathogenität schließen. Insertions- und Deletions-Polymorphismen führen meist zu schwerwiegenderen Veränderungen als Punktmutationen. Hierbei werden eine oder mehrere Basen aus der DNA entfernt bzw. eingefügt. Dies führt zu einer Verschiebung des Leserasters (,frame shift“) bei der Synthese von Proteinen und damit zu einer veränderten Aminosäuresequenz und einem völlig anderen Protein.

Genpolymorphismen können unterschiedliche Folgen verursachen. Es sind Auswirkungen auf die Genexpression, die posttranskriptionale Modifikation, und die Menge und Eigenschaften des Genprodukts bekannt. Es können andere Proteine entstehen, die eine verbesserte oder verringerte Funktion im Vergleich zum ursprünglichen Protein haben. So können sowohl Krankheiten als auch evolutionäre Vorteile bei Personen mit einer bestimmten Genmutation entstehen. Auf die Expressivität eines Genabschnittes können sich Polymorphismen auswirken, wenn sie in der Promotorregion eines Gens liegen. So kommt es bei bestimmten Mutationen zu einer vermehrten oder verringerten Produktion bestimmter Proteine (Buselmaier und Tariverdian 2007). 


\subsubsection{Genpolymorphismen mit Einfluss auf das Herz-Kreislauf- System}

Es sind bereits mehrere Genpolymorphismen bekannt, die bei der Regulation des HerzKreislauf-Systems eine Rolle spielen. Popov et al. untersuchten 2008 den Einfluss des ACE-I/D-Polymorphismus des Angiotensin-Converting-Enzyme-1-Gens auf die perioperative Hämodaynamik. Das Angiotensin-Converting-Enzyme katalysiert im Körper die Umwandlung von Angiotensin $1 \mathrm{zu}$ Angiotensin 2. Angiotensin 2 fungiert als Vasokonstriktor und bewirkt eine Blutdrucksteigerung. In der Studie konnte zwar kein Unterschied bezüglich der systemischen Hämodynamik während Herzoperationen mit HLM festgestellt werden, es zeigten sich jedoch postoperativ vorübergehende Unterschiede in der pulmonalen Hämodynamik. Es wäre möglich, dass diese Unterschiede zwischen den Genotypen auf Veränderungen der Serumaktivität von ACE beruhen (Popov et al. 2008).

Rossi et al. zeigten im Jahr 2003, dass der T-786C-Polymorphismus des eNOS(endotheliale NO-Synthase-) Gens einen Einfluss auf das Risiko der Entwicklung einer koronaren Herzerkrankung bei Kaukasiern hat. C-Allelträger hatten ein signifikant erhöhtes Risiko für die Entwicklung einer 2- oder 3-Gefäßerkrankung der Koronararterien. Die eNOS ist ein Enzym, das die Bereitstellung von NO (Stickstoffmonoxid) aus dem Endothel katalysiert. NO sorgt unter anderem dafür, dass in der Peripherie Gefäße weit gestellt werden. Bei C-Allelträgern geht man von einer verminderten Transkriptionsrate der eNOS aus, sodass es in der Folge auch zu geringeren NO-Konzentrationen im Blut bei diesen Individuen kommt. Die verminderte Fähigkeit zur Vasodilatation könnte bei Individuen, die oxidativem Stress wie beispielsweise bei einer arteriellen Hypertonie ausgesetzt sind, ausschlaggebend für einen schlechteren Verlauf und die Entwicklung von Atherosklerose sein (Rossi et al. 2003).

Ein ähnliches Ergebnis konnten auch Colombo et al. 2003 aufweisen. Sie belegten ebenfalls den Zusammenhang zwischen dem eNOS-T-786C-Polymorphismus und dem Vorliegen einer koronaren Herzerkrankung. Zusätzlich konnten sie einen solchen Zusammenhang auch bei einem weiteren Polymorphismus der eNOS (Glu298Asp) nachweisen. Lag bei einem Individuum sogar bei beiden Polymorphismen das Risikoallel (C und Asp/Asp) vor, so ging dies mit einem zusätzlich erhöhten Risiko für eine koronare Herzerkrankung einher. 


\subsubsection{Genpolymorphismen mit Einfluss auf die Nierenfunktion}

Einige genetische Polymorphismen sind bereits als Faktoren für das Auftreten und Fortschreiten einer Nierenfunktionsstörung nach Operationen mit Herz-LungenMaschine identifiziert worden. So konnten Stafford-Smith et al. 2005 gleich mehrere Polymorphismen identifizieren, die einen Einfluss auf die postoperative Nierenfunktion nach Herzoperation mit HLM haben. Sie belegten, dass Genpolymorphismen die Nierenfunktion hauptsächlich über erhöhte Entzündungsreaktionen in der Niere und/ oder erhöhte vasokonstriktorische Impulse beeinflussen. Im Rahmen ihrer Studie untersuchten sie 1768 Patienten, die sich einer elektiven aorto-koronaren Bypassoperation unterzogen, mithilfe der Bestimmung des prozentualen KreatininAnstiegs nach der Operation im Vergleich $\mathrm{zu}$ vorher. Dabei ergab sich, dass insbesondere die Kombination von zwei Genpolymorphismen (beispielsweise AGT842C und IL6-572C) mit erhöhten postoperativen Kreatinin-Werten assoziiert ist. So treten bei dieser Genkombination erhöhte Entzündungswerte sowie Endotoxinspiegel im Blut auf, welche mit einer Nierenschädigung im Zusammenhang stehen können. Des Weiteren zeigte sich ein erhöhtes Risiko einer Nierenschädigung bei Genpolymorphismen-Kombinationen, bei denen mindestens eine mit einer erhöhten Vasokonstriktion der Niere assoziiert ist. Unter der Vasokonstriktion wird die Nierendurchblutung der Niere verringert, was zu einer Schädigung des Organs führen kann.

Popov et al. konnten 2009 einen weiteren Polymorphismus identifizieren, der mit einem postoperativen Nierenversagen assoziiert ist, indem sie einen Zusammenhang zwischen dem eNOS-T-786C-Polymorphismus und einem postoperativen Nierenversagen nachwiesen. In ihrer Studie zeigten sie, dass in der Risikogruppe der CAllelträger ein signifikant erhöhter Bedarf einer Nierenersatztherapie bestand sowie eine geringere minimale Kreatinin-Clearance und ein stärkerer Abfall der KreatininClearance postoperativ (Popov et al. 2009). Bei C-Allelträgern liegt eine verminderte Transkription der eNOS vor, was in einer geringeren Konzentration des Vasodilatators NO im Blut resultiert. Dadurch kommen vermehrt vasokonstriktorische Einflüsse zur Geltung, mit den bereits beschriebenen Auswirkungen auf die renale Hämodynamik.

Pinto-Sietsma et al. untersuchten im Jahr 2003, ob der EDN1 Polymorphismus des Endothelin 1-Gens einen Einfluss auf eine Verminderung der glomerulären Filtrationsrate (GFR) oder eine Mikroalbuminurie hat. Sie konnten zeigen, dass ein 
signifikanter Zusammenhang zwischen dem EDN1-G-N-Haplotyp und einer verminderten GFR besteht. Endothelin 1 (ET1) bedingt unter anderem eine Vasokonstriktion von Blutgefäßen der Niere und der Mesangiumzellen sowie der Proliferation von Glomeruluszellen und der extrazellulären Matrix. Liegt nun aufgrund eines bestimmten Genotyps eine erhöhte ET1-Konzentration im Blut vor, kann dies zu einer vermehrten Vasokonstriktion führen und dann in einer verminderten GFR resultieren. Die zusätzliche Stimulation der verschiedenen Nierenzellen kann zu einer intrarenalen Gefäßerkrankung und Glomerulosklerose führen, was einen weiteren Einfluss auf die Hämodynamik der Niere hat und über längere Zeit einen Abfall der GFR bedingen kann.

Auch Chew und Mitarbeiter konnten im Jahr 2000 einen Zusammenhang zwischen einem Genpolymorphismus und einem postoperativen Nierenversagen nachweisen. Die Genotypen $\varepsilon 3$ und $\varepsilon 2$ des APO-E-Gens zeigten einen vermehrten Anstieg des Serumkreatinins nach Herzoperation im Gegensatz zum $84-G e n o t y p$ (Chew et al. 2000). Man nimmt an, dass die Ursache dafür im veränderten Lipidstoffwechsel und erhöhten Risiko für Atherosklerose liegt, da diese schon in mehreren Studien als Risikofaktor für eine postoperative Nierenschädigung genannt sind (Davila-Roman et al. 1999; Hosaka et al. 1994; Nypaver et al. 1993).

\subsubsection{Der EPO-SNP-rs1617640-Polymorphismus}

In dieser Studie wurde ein ganz bestimmter Polymorphismus untersucht. Dabei handelt es sich um den SNP-rs1617640-Polymorphismus von Erythropoietin. SNP bedeutet single nucleotide polymorphism (auf Deutsch: Einzelnukleotid-Polymorphismus). Das bedeutet, dass eine einzige Base im Gen verändert sein kann, in diesem Fall entweder ein Thymin (T) oder ein Guanin (G). Da jeder Mensch 2 Kopien an Erbmaterial besitzt, können also folgende Konstellationen entstehen: homozygot TT (wurde in anderen Studien als Risikoallel identifiziert), heterozygot TG oder homozygot GG.

Dieser SNP-Polymorphismus findet sich an der Stelle rs1617640 und damit im Promotor des EPO-Gens. Der Promotor ist der Genabschnitt, der vor einer zu transkribierenden Basenabfolge liegt und reguliert, ob die DNA an dieser Stelle abgelesen wird und mRNA zur Bildung von Proteinen entsteht. Man geht davon aus, 
dass beim TT-Genotyp die Aktivität des Promotors erhöht ist. Es kommt somit zu einer gesteigerten mRNA-Produktion und in der Folge $\mathrm{zu}$ einer vermehrten Bildung von Erythropoietin.

Tong et al. zeigten 2008, dass das T-Allel von SNP-rs1617640 im Promotor des EPO-Gens mit dem vermehrten Auftreten von proliferativer diabetischer Retinopathie $(\mathrm{PDR})$ und terminaler Niereninsuffizienz (ESRD = end stage renal disease) assoziiert ist. In Zusammenhang damit konnten sie ebenfalls feststellen, dass die EPOKonzentration im menschlichen Körper beim risikoassoziierten TT-Genotyp 7,5mal höher war als beim GG-Genotyp. In ihrer Studie untersuchten sie mehrere Kohorten (europäisch-amerikanisch) mit Diabetes mellitus und den Komplikationen einer PDR und ESRD auf 19 unterschiedliche Genpolymorphismen und verglichen diese mit einer Kontrollgruppe aus Individuen mit Diabetes mellitus, aber ohne die beiden genannten Komplikationen. Sie konnten einen signifikanten Zusammenhang beim EPO-SNPrs1617640 Polymorphismus für sowohl die Entwicklung einer terminalen Niereninsuffizienz als auch die Entwicklung einer diabetischen Retinopathie finden.

Ein Grund für diese Ergebnisse könnte die erhöhte EPO-Konzentration bei Individuen mit dem Risikoallel $\mathrm{T}$ sein. EPO codiert für einen potenten Angiogenesefaktor, der in der Netzhaut des Auges und der Niere exprimiert wird. Eine hohe EPO-Konzentration im menschlichen Körper zeigt eine starke Assoziation mit PDR, wie Watanabe et al. in einer Studie im Jahr 2005 zeigen konnten. Der Grund ist eine ausgeprägte Neovaskularisation im Auge bei hohen EPO- Konzentrationen, die sich aber unter Inhibition von EPO erfolgreich unterdrücken lässt (Watanabe et al. 2005). Die Höhe der EPO-Konzentration im Körper spielt folglich eine entscheidende Rolle. So ist nachgewiesen, dass Patienten, die aufgrund einer Anämie beruhend auf einer Niereninsuffizienz mit EPO behandelt werden, eine höhere Rate an kardiovaskulären Komplikationen aufweisen, wenn ihre Hämoglobin-(Hb-)Level im höheren Bereich liegen (13,5 g/dl) als Patienten, bei denen die Hb-Level niedriger sind $(11,3 \mathrm{~g} / \mathrm{dl})$ (Singh et al. 2006). Ein ähnlicher Effekt von EPO auf die Verschlechterung einer Niereninsuffizienz ist bereits 1988 von Garcia et al. beschrieben worden. Des Weiteren ist bekannt, dass höhere EPO-Dosen mit einem vermehrten Auftreten einer PRD bzw. einer Verschlechterung des Befundes assoziiert sind (Diskin et al. 2007). 


\section{$1.4 \quad$ Zielsetzung}

Einige genetische Polymorphismen sind bereits als Faktoren für das Auftreten und Fortschreiten einer Nierenfunktionsstörung nach Herzoperation mit Einsatz der HerzLungen-Maschine identifiziert worden, darunter Polymorphismen der Gene von IL6, Angiotensinogen, ACE, Apolipoprotein E und eNOS (Chew et al. 2000; Haase-Fielitz et al. 2007; Isbir et al. 2007; Popov et al. 2009; Stafford-Smith et al. 2005).

Tong et al. konnten 2008 in einer Studie nachweisen, dass das T-Allel von SNPrs1617640 in der Promotorregion des EPO-Gens einen signifikanten Zusammenhang mit proliferativer diabetischer Retinopathie (PDR) und Nierenversagen im Endstadium (end stage renal disease $=$ ESRD) aufweist. Unter anderem wurde gezeigt, dass die EPO-Konzentration im Blut bei Menschen mit dem TT-Risiko-Genotyp 7,5mal höher war als bei denen mit GG- Genotyp (Tong et al. 2008).

Basierend auf der Annahme, dass EPO mit thrombembolischen Ereignissen assoziiert ist und den beschriebenen risikoassoziierten Eigenschaften des T-Allels, wäre es möglich, dass dieser Polymorphismus auch einen Einfluss auf ein postoperatives Nierenversagen bei Patienten nach Herzoperation mit Anschluss an die Herz-LungenMaschine hat.

Das Ziel der aktuellen Studie ist es, den EPO-SNP-rs1617640-Polymorphismus bei Patienten zu erforschen, die sich einer Herzoperation mit Einsatz der Herz- LungenMaschine unterziehen, und seine Rolle als prädisponierenden Faktor für eine postoperative Nierenfunktionsstörung zu ermitteln. Diese Daten könnten zu einer Risikoeinschätzung bezüglich einer möglichen Nierenschädigung nach einer Herzoperation beitragen und somit bereits präoperativ helfen, Hochrisikopatienten zu identifizieren. 


\section{Material und Methoden}

\subsection{Patientenkollektiv}

Ziel dieser prospektiven Studie war es, den Einfluss des genetischen Polymorphismus SNP rs1617640 im Promotor des EPO-Gens auf die Entstehung und den Schweregrad eines akuten Nierenversagens anhand des RIFLE-Scores zu untersuchen. In die Studie eingeschlossen wurden 500 Patienten, die sich zwischen November 2005 und Dezember 2006 in stationärer Behandlung des Universitätsklinikums Göttingen befanden und einer Herzoperation mit Anwendung der Herz-Lungen-Maschine unterziehen mussten. Als Ausschlusskriterien galt ein Alter $<18$ Jahre oder $>80$ Jahre sowie bekannte neoplastische Erkrankungen. Des Weiteren wurden drei Patienten mit chronischer Niereninsuffizienz und Dialysepflichtigkeit sowie Nierentransplantierte von der Studie ausgeschlossen. Bei 16 der untersuchten Patienten ließ sich keine Genotypisierung durchführen, sodass auch diese Patienten von der Studie ausgeschlossen wurden. Es ergab sich also ein endgültiges Kollektiv von 481 untersuchten Patienten.

Die Aufklärung der Patienten umfasste die Ziele der Studie, die studienspezifische Blutentnahme von $5 \mathrm{ml}$, die Auswertung der Daten und die Freiwilligkeit der Teilnahme an der Studie. Bei HLM-Patienten erfolgte dies präoperativ. Da dies bei den meisten polytraumatisierten oder langzeitbeatmeten Patienten jedoch nicht möglich war, erfolgte in diesem Falle eine Einwilligung nach eingehender Information des vom zuständigen Vormundschaftsgerichts bestellten Betreuers. Wurde kein Betreuer gerichtlich bestellt, so wurde der „mutmaßliche Wille“ des Patienten durch die nächsten Angehörigen erfragt. Erst nach der schriftlichen Einwilligung wurde mit der Datenerhebung begonnen und die Blutentnahme durchgeführt.

Die Durchführung der Studie wurde nach Einwilligung der ortsansässigen Ethikkommission der Medizinischen Fakultät realisiert. 


\section{$2.2 \quad$ Datenerhebung}

Die gesammelten Daten der Studienteilnehmer wurden in folgende vier Kategorien unterteilt:

1.) Allgemeine Patientendaten

2.) Präoperative Daten

3.) Intraoperative Daten

4.) Postoperative intensivmedizinische Überwachung.

Die gesamten Daten wurden anhand von Arztbriefen der Hausärzte, Verlegungsberichten von externen Häusern sowie den Operationsberichten und den täglichen Visiten der operativen Intensivstationen 0117 und 0118 im Universitätsklinikum Göttingen zusammengetragen.

\subsubsection{Allgemeine Patientendaten}

Für die allgemeinen Patientendaten wurden Name, Geschlecht, Geburtsdatum, Adresse, Größe und Gewicht erfragt und in die Datenbank eingegeben. Die Daten wurden entweder direkt von den Patienten angegeben oder aus vorliegenden Aufnahmeprotokollen und Arztbriefen übernommen. Des Weiteren wurde das Datum der Aufnahme in das Krankenhaus bzw. auf die Intensivstation sowie die jeweilige Entlassung festgehalten; gegebenenfalls wurde auch der Zeitpunkt des Todes notiert. Vor der Auswertung der Daten erfolgte eine Pseudonymisierung mit Hilfe von Zahlen. 


\subsubsection{Präoperative Daten}

Zusätzlich zu den allgemeinen Patientendaten wurden vor der Operation bestimmte Risikofaktoren bei den Patienten erfragt. Besonders wichtig im Hinblick auf die Studie waren dabei die Raucheranamnese, das Vorbestehen einer kardialen Erkrankung, z.B. Angina pectoris, Koronare Herzkrankheit (KHK) oder Herzinsuffizienz sowie Vorerkrankungen wie arterieller Hypertonus, Hyperlipoproteinämie und Diabetes mellitus. Außerdem wurde ggf. das Vorliegen einer Niereninsuffizienz, Dialysepflichtigkeit oder einer peripheren arteriellen Verschlusskrankheit (PAVK) erfasst. Des Weiteren wurde festgehalten, ob eine chronisch obstruktive Lungenerkrankung (COPD) oder ein pulmonaler Hypertonus vorlag, ob bereits schon einmal ein zerebrales Ereignis stattgefunden hatte und ob bei dem Patienten ein Krebsleiden bekannt war.

Die Risikofaktoren wurden anhand folgender Kriterien festgemacht:

- Positive Familienanamnese: KHK oder stattgehabter Myokardinfarkt bei Verwandten 1. Grades

- Arterieller Hypertonus

- Hyperlipoproteinämie

- Nikotinabusus

- Diabetes mellitus

- Zerebrale Ereignisse: Apoplex, transitorisch ischämische Attacken (TIA), prolongierte reversible Ischämie mit neurologischem Defizit (PRIND)

- Koronare Herzerkrankung: abgelaufener Myokardinfarkt mit ggf. therapeutischer Versorgung (PTCA, BypassOperation), positiver Herzkatheterbefund

- Herzinsuffizienz: Einteilung nach der NYHA-Klassifikation

- Angina pectoris (AP): Einteilung nach der CSS-Klassifikation

- Renale Dysfunktion: anamnestisch Serum-Kreatininwerte von $>1,5 \mathrm{mg} / \mathrm{dl}$ 
Ebenfalls festgehalten wurde die Vormedikation bei den Patienten. $\mathrm{Zu}$ den als für die Studie relevant betrachteten Medikamenten zählten $\beta$-Blocker, ACE-Hemmer, Koronartherapeutika (z.B. Molsidomin oder Nitrate), andere Antihypertensiva (z.B. Ca ${ }^{2+}$ Antagonisten oder AT-1-Blocker (Angiotensin-1-Blocker)) sowie Antiarrhythmika. Auch die Anwendung von Lipidsenkern, Antidiabetika, Diuretika und Bronchodilatatoren wurde notiert. Eine Antikoagulation innerhalb der letzten sechs Monate vor der Operation wurde ebenfalls festgehalten.

\subsubsection{Intraoperative Daten}

Neben der Dringlichkeit der Operation (elektiv, dringlich oder Notfall) wurde zunächst die Aortenklemmzeit und die Zeit der Anbindung an die Herz-Lungen-Maschine notiert. Des Weiteren wurde festgehalten, welche Art eines aorto-koronaren Bypasses gelegt wurde (versorgter Koronargefäßast sowie die Herkunft des Anschlussgefäßes: Vene oder Arterie). Im Falle eines Klappenersatzes wurde die versorgte Klappe notiert. Sofern Blutprodukte transfundiert werden mussten, wurde sowohl die Anzahl als auch die Qualität (Erythrozytenkonzentrat, Thrombozytenkonzentrat oder Frischplasma (FFP)) vermerkt.

Operationen wie eine Resektion bei hypertroph obstruktiver Kardiomyopathie (HOCM), ein Ersatz bzw. Teilersatz des Aortenbogens sowie der Verschluss eines Atrioseptalen Defekts (ASD) oder Ventrikelseptumdefekts (VSD) waren seltener, wurden aber dennoch in die Datenerhebung einbezogen.

Die während der Operation verabreichten Medikamente zur Kreislaufunterstützung wurden ebenfalls festgehalten. Dazu zählten Nitroglycerine, Nitroprusside, NO, Kortison, Trasylol, Tranexamsäure, Suprarenin, Perfan, Arterenol, Levosimendan und Cordarex.

Sofern die Implantation eines Herzschrittmachers oder der Einbau einer intraaortalen Ballonpumpe (IABP) zur Entlastung des Herzens durchgeführt wurde, wurde dies vermerkt. 


\subsubsection{Postoperative intensivmedizinische Überwachung}

Die Daten für die postoperative intensivmedizinische Überwachung stammen aus der täglichen Visite, in der retrospektiv die Daten der jeweils letzten 24 Stunden gesammelt wurden. Diese täglichen Visiten wurden während des gesamten Aufenthaltes der Patienten auf der Intensivstation 0117 bzw. 0118 durchgeführt. Hämodynamische Messwerte wurden über die routinemäßig benutzten bettseitigen Monitoring-Systeme der Intensivstation elektronisch gespeichert. Von den kontinuierlich gemessenen Werten wie Herzfrequenz, Blutdruck und Atemfrequenz wurde täglich der jeweilige Mittelwert erfasst.

$\mathrm{Zu}$ den untersuchten relevanten Kreislaufparametern zählten:

- Elektrokardiogramm (EKG)

- Messung des arteriellen Blutdrucks

- $\quad$ Messung des zentralen Venendrucks (ZVD)

- Pulmonaliskatheter (Swan-Ganz-Katheter) als erweiterte hämodynamische Messung

- Pulscontour Continouus Cardiac Output (PICCO).

Nierenfunktion:

Zur Einteilung der Schweregrade des akuten Nierenversagens wurde 2004 der RIFLEScore eingeführt (Renz-Polster und Krautzig 2008). Die Buchstaben R (Risk), I (Injury), F (Failure), L (Loss of function) und E (End stage renal failure) stehen hier für die bestimmten Stadien der Nierenschädigung. Alternativ dazu wurden 2007 die AKINStadien 1 - 3 entwickelt, die den Buchstaben R, I und F beim RIFLE-Score entsprechen (Renz-Polster und Krautzig 2008). Eine Übersicht über beide Scores liefert Tabelle 1. 
Tabelle 1: Schweregradeinteilung der Nierenschädigung (abgewandelt aus Renz-Polster et al. 2008, S.986)

\begin{tabular}{|c|c|c|c|c|c|}
\hline AKIN & 1 & 2 & 3 & Nicht & definiert \\
\hline $\begin{array}{l}\text { Urin- } \\
\text { aus- } \\
\text { schei- } \\
\text { dung }\end{array}$ & $\begin{array}{l}<0,5 \mathrm{ml} / \mathrm{kg} / \mathrm{h} \\
\text { über mehr als } \\
6 \text { Stunden }\end{array}$ & $\begin{array}{l}<0,5 \mathrm{ml} / \mathrm{kg} / \mathrm{h} \\
\text { über mehr als } \\
12 \text { Stunden }\end{array}$ & $\begin{array}{l}<0,3 \mathrm{ml} / \mathrm{kg} / \mathrm{h} \text { über } \\
\text { mehr als } 24 \text { Stunden } \\
\text { oder Anurie über } 12 \\
\text { Stunden }\end{array}$ & $\begin{array}{l}\text { Nieren- } \\
\text { versagen }\end{array}$ & $\begin{array}{l}\text { Nieren- } \\
\text { versagen }\end{array}$ \\
\hline $\begin{array}{l}\text { Serum- } \\
\text { Krea- } \\
\text { tinin }\end{array}$ & $\begin{array}{l}\text { Anstieg um } \\
0,3 \mathrm{mg} / \mathrm{dl} \\
\text { oder das 1,5- } \\
2 \text { fache des } \\
\text { Ausgangs- } \\
\text { wertes }\end{array}$ & $\begin{array}{l}\text { Anstieg um } \\
\text { das 2- 3fache } \\
\text { des } \\
\text { Ausgangs- } \\
\text { wertes }\end{array}$ & $\begin{array}{l}\text { Anstieg um mehr als } \\
\text { das } 3 \text { fache des } \\
\text { Ausgangswertes oder } \\
\text { Serum-Krea }>4 \mathrm{mg} / \mathrm{dl} \text {, } \\
\text { Anstieg um } \\
\text { mindestens } 0,5 \mathrm{mg} / \mathrm{dl} \\
/ \text { Tag }\end{array}$ & $\begin{array}{l}\text { über } \\
\text { mehr als } \\
4 \\
\text { Wochen }\end{array}$ & $\begin{array}{l}\text { über } \\
\text { mehr als } \\
3 \text { Monate }\end{array}$ \\
\hline RIFLE & Risk & Injury & Failure & Loss & ESKD \\
\hline
\end{tabular}

Für die Beurteilung eines akuten Nierenversagens wurde im Verlauf des Aufenthaltes auf der Intensivstation bei allen Patienten eine strenge Überwachung der Nierenparameter vorgenommen. Zu den aufgezeichneten Nierenfunktionsparametern zählten das maximale Serumkreatinin (mg/dl), der Serumkreatinin-Anstieg in \%, die minimale KreatininClearance $(\mathrm{ml} / \mathrm{min})$, die Veränderung der Kreatinin-Clearance $(\mathrm{ml} / \mathrm{min})$ und der maximale Serum- Harnstoff (mg/dl). Außerdem wurde geprüft, ob die Patienten eine diuretische Therapie benötigten und ob eine Nierenersatztherapie erforderlich war. Weitere überprüfte Parameter waren S-CPK (U/1), S-CPK-MB (U/1), Kalium und Laktat. Der RIFLE-Score wurde für den ersten postoperativen Tag ermittelt und notiert.

Da sich ein Nierenversagen nicht nur in einer Erhöhung der Retentionsparameter äußern kann, wurden auch die Blutwerte jedes Patienten täglich überwacht. Die Niere hat durch die Bildung des Hormons Erythropoietin einen maßgeblichen Einfluss auf die Bildung der Erythrozyten, sodass es im Verlauf eines Nierenversagens unter anderem zu Verminderungen des Hämatokrits (Hkt) kommen kann. Gemessen wurde der minimale Hämatokrit in \%.

Die Indikation für eine Nierenersatztherapie $(\mathrm{CVVH}=$ Kontinuierliche venovenöse Hämofiltration) wurde gestellt, wenn der mit einer Anurie einhergehende Ausfall der Nierenfunktion die Funktion anderer Organe beeinträchtigte, (z.B. durch eine 
Volumenüberladung), oder eines der folgenden absoluten Kriterien für eine Nierenersatztherapie erfüllt war:

- Diuretikaresistente Flüssigkeitsüberladung

- Therapierefraktäre Hyperkaliämie (> 6,5 mmol/1)

- Metabolische Azidose

- Urämiesymptome (Enzephalopathie, Neuropathie, Perikarditis, Azidose mit $\mathrm{pH}<7,0)$

Entstanden während des postoperativen Verlaufs Komplikationen, wie beispielsweise Reanimationspflichtigkeit, Defibrillation oder Asystolie, so wurde dieses notiert. Als Mortalität im Krankenhaus wurde der Tod während des operationsbedingten Krankenhausaufenthaltes definiert, unabhängig von der Ursache.

\subsection{Genotypisierung}

Von jedem Probanden wurde postoperativ der EPO-rs1617460-Genotyp aus der DNA bestimmt. Hierzu wurde jedem Patienten vor der Operation $5 \mathrm{ml}$ Blut entnommen und die gewonnene Blutprobe bis zur weiteren Verarbeitung eingefroren und so konserviert. Im weiteren Verlauf wurde dann die DNA aus dem Blut isoliert und eine Real-Time-PCR durchgeführt.

\subsubsection{DNA- Isolierung}

Den Gewinn von reiner DNA aus Vollblut bezeichnet man als DNA-Isolierung, die in drei Schritte unterteilt werden kann. Zur Durchführung dieser Schritte wird der QIAmp® Mini Kit (QIAGEN Germany, Hilden) verwendet. 
1. Lyse

$\mathrm{Zu} 200 \mu \mathrm{l}$ antikoaguliertem EDTA-Blut werden $20 \mu \mathrm{l}$ Proteinkinase-K gegeben. Dadurch werden die darin enthaltenen Leukozyten lysiert und ihre DNA freigesetzt. Danach werden dem Gemisch $200 \mu$ l AL-Puffer zugefügt. Das Gemisch wird für 15 Sekunden in einem MS2-Minishaker von IKA-Schütt ${ }^{\circledR}$ gut durchmischt und bei $56{ }^{\circ} \mathrm{C}$ über Nacht inkubiert.

\section{Waschung}

Am folgenden Tag wird die Lösung in einer Eppendorf- Zentrifuge kurz anzentrifugiert und zur Fällung der DNA mit $200 \mu 100$ \%igem Ethanol versetzt, um eine eventuelle Kreuzkontamination zu vermeiden.

Anschließend trägt man $700 \mu 1$ dieser Lösung auf eine Säule auf, die in einer Collection-Tube steht, die wiederum als Auffanggefäß dient. Alles zusammen wird dann eine Minute lang bei $8000 \mathrm{rpm}$ (rounds per minute $=$ Umdrehungen pro Minute) zentrifugiert. Nach Ablauf der Minute wird die Säule in ein neues Auffanggefäß gestellt und mit $500 \mu \mathrm{l}$ AW1-Puffer versetzt, um anschließend wieder bei $8000 \mathrm{rpm}$ für eine Minute zentrifugiert $\mathrm{zu}$ werden. Wie bereits nach der ersten Zentrifugierung wird ein neues Auffanggefäß benötigt. In einem nächsten Schritt werden $500 \mu 1$ eines AW2-Puffer hinzugegeben und anschließend wird bei nun $13000 \mathrm{rpm}$ für drei Minuten zentrifugiert. Nach diesem Vorgang wird die Säule auf das letzte bereitstehende Auffanggefäß gesetzt und 1,5 Minuten bei $13000 \mathrm{rpm}$ trocken zentrifugiert.

\section{Elution}

Die Säule wird im Anschluss auf ein steriles E-Cup gestellt. Zur Elution der DNA werden $50 \mu$ eines AE-Puffers hinzugefügt, ohne dass dabei die Membran berührt wird. Darauf folgt eine Inkubation der Säule bei Raumtemperatur für wiederum eine Minute, um anschließend zum letzten Mal bei $8000 \mathrm{rpm}$ für eine weitere Minute zu zentrifugieren. Die nun eluierte DNA kann entweder über eine relativ lange Zeit bei $\quad-20{ }^{\circ} \mathrm{C}$ stabil gelagert werden oder direkt in der PCR weiter verwendet werden.

Im Rahmen dieser Studie wurden $5 \mu$ des DNA-Templates mit $45 \mu$ l HPLC- $\mathrm{H}_{2} \mathrm{O}$ gemischt und im Anschluss kurz „gevortext“ und anzentrifugiert. Die photometrische 
Konzentrationsbestimmung wurde bei den Wellenlängen $260 \mathrm{~nm}$ und $280 \mathrm{~nm}$ am Spektralphotometer BIOMATe5 ${ }^{\circledR}$ durchgeführt. Um davon ausgehen zu können, dass eine sicher reine DNA vorliegt, bestimmt man den Quotienten der Extinktion von 260 und $280 \mathrm{~nm}$. Bei gut gereinigten Proben sollte dieser Quotient im Bereich zwischen 1,5 und 2,0 liegen.

\subsubsection{Polymerasekettenreaktion (PCR)}

Bei der Polymerasekettenreaktion $(\mathrm{PCR}=$ polymerase chain reaction) handelt es sich um eine chemische Methode, bei dem ein durch Extraktion gewonnener DNA-Abschnitt selektiv vervielfältigt werden kann. Es handelt sich dabei um ein zyklisches Verfahren, bei dem sich im Idealfall pro Durchgang die Anzahl der betrachteten DNA-Abschnitte verdoppelt. Diese Methode ist Voraussetzung dafür, die amplifizierte DNA in der Folge im Labor sequenzieren zu können und somit die exakte Basenabfolge zu verifizieren.

Die PCR lässt sich in die vier folgenden Schritte einteilen:

\section{Denaturierung}

Die isolierte Doppelstrang-DNA wird auf $94{ }^{\circ} \mathrm{C}$ erhitzt. Durch die hohe Temperatur werden Wasserstoffbrückenbindungen, die die DNA-Doppelstränge zusammenhalten, gelöst. Die DNA liegt nun in Einzelsträngen vor.

\section{Annealing:}

Im Folgenden wird die Temperatur wieder gesenkt und auf einem Niveau gehalten, die eine spezifische Anlagerung von Primern an die DNA erlaubt. Primer sind kurze Nukleotid-Abfolgen, welche selektiv an bestimmte DNA-Abschnitte binden und die Ansatzstelle für die DNA-Polymerase darstellen. Die Primer müssen spezifisch für den gesuchten DNA-Abschnitt gewählt werden, zu dem sie komplementär sind. Die ideale Temperatur für die Anlagerung der Primer liegt normalerweise $2-3{ }^{\circ} \mathrm{C}$ unter dem Schmelzpunkt der Primersequenzen; dies entspricht hier einer Temperatur von $58^{\circ} \mathrm{C}$. 


\section{Extending}

Die Temperatur wird anschließend wieder auf $72{ }^{\circ} \mathrm{C}$ erhöht und eine hitzestabile TaqPolymerase wird zugesetzt. Diese DNA-Polymerase katalysiert nun die Verlängerung der mit Primern markierten DNA-Abschnitte. Dafür müssen dem Reaktionsgefäß freie Nukleotide (in der Form von Desoxynukleosidtriphosphaten) zugesetzt werden, die dann durch die Taq-Polymerase $\mathrm{zu}$ einem neuen komplementären DNA-Strang zusammengesetzt werden. Die Polymerase beginnt am 3'-Ende des angelagerten Primers und folgt dann dem DNA-Strang. Der Primer wird nicht wieder abgelöst, er bildet den Anfang des neuen Einzelstrangs.

\section{Wiederholung}

Die ersten drei Schritte werden nun beliebig oft wiederholt, was jedes Mal zu einer Verdopplung des DNA-Materials führt. Nach etwa 20 Zyklen sind aus einem DNADoppelstrang ca. 20 Millionen neue DNA-Moleküle entstanden.

\subsubsection{Allelische Diskriminierung mittels Real-Time-PCR}

Das Real-Time-(Echtzeit-)PCR-Verfahren mittels TaqMan-Methode wird im Rahmen von Genotypisierungen verwendet, um SNPs (Single Nucleotide Polymorphisms = Einzelnukleotid Polymorphismen) zu detektieren.

In der Probe befindet sich neben den beiden Primern auch eine fluoreszenzmarkierte Sonde, die an eine Gensequenz zwischen den beiden Primern bindet. Diese Sonde besteht aus einer Oligonukleotidsequenz, die mit zwei Fluoreszenzfarbstoffen markiert ist. Am 5'-Ende der Sonde befindet sich das Reportermolekül und am 3'-Ende der Quencher. Der Reporter und der Quencher befinden sich also in räumlicher Nähe zueinander, was die Voraussetzung für den Fluoreszenz-Energie-Transfer (FRET) ist. Dabei wird bei einer Wellenlänge von $488 \mathrm{~nm}$ der Reporter vom Laserlicht angeregt und emittiert Photonen, die dann vom Quencher aufgenommen und als Licht seiner speziellen Wellenlänge emittiert werden. Es wird also ausschließlich vom Quencher Licht emittiert. 
Während der PCR wird der PCR-Primer mit Hilfe der Taq-Polymerase so lange verlängert, bis diese auf die Sonde trifft. Dort spaltet sie den Reporter von der Sonde ab, wodurch Reporter und Quencher ihre räumliche Nähe zueinander verlieren. Da nun kein Energietransfer mehr stattfinden kann, fluoresziert jetzt der Reporterfarbstoff entsprechend seiner spezifischen Wellenlänge. Das Fluoreszenzsignal des Reporters ist proportional zur Anzahl der gebundenen und dann gespaltenen Sonden und steigt proportional zur Menge der gebildeten PCR-Produkte an. Während der gesamten PCR wird die Fluoreszenzemission detektiert und auf einen internen Standard normiert.

Die Real-Time-PCR wird typischerweise im Rahmen von Genexpressionsanalysen sowie bei der allelischen Diskriminierung von SNPs angewendet. Bei Genotypisierungen mittels Real-Time-PCR werden zwei Sonden eingesetzt, die den komplementären Basensequenzen der zwei verschiedenen Allele entsprechen. Die Sonden sind mit fluoreszierenden Reportern unterschiedlicher Wellenlänge markiert, die als VIC und FAM bezeichnet werden. VIC fluoresziert bei 550 nm und FAM bei $520 \mathrm{~nm}$. So können die zwei verschiedenen Allele in der Endpunktmessung unterschieden werden. Die Taq-Polymerase spaltet ausschließlich Sonden, die absolut spezifisch und vollständig an die Matrizen-DNA binden. Hingegen werden Sonden, die nicht spezifisch binden, ohne Spaltung entfernt, und es kommt zu keinem Fluoreszenzsignal der Reporter. Um eine unspezifische Bindung herbeizuführen und somit eine Spaltung zu verhindern, reicht schon der Austausch einer einzigen Base, sodass dieses Verfahren eine Detektion von SNPs ermöglicht. Entsprechend der unterschiedlich fluoreszierenden Reporter- Farbstoffe kann grafisch das Verhältnis von VIC und FAM bzw. das der Allele zueinander ermittelt werden.

Für die Detektion der SNPs wurde nach Assay ID C_8786860_10 von Applied Biosystems, Darmstadt, Deutschland vorgegangen. Zunächst wurde der Master Mix für 481 DNA-Proben erstellt, gevortext und kurz anzentrifugiert.

Master Mix (pro DNA-Probe):

$\begin{array}{llll}\text { 2x TaqMan Master Mix } & 2,500 & \mu l & \text { (Applied Biosystems, Darmstadt) } \\ \mathrm{ddH}_{2} \mathrm{O} & 1,375 & \mu \mathrm{l} & \\ \text { Assay Mix 40X } & 0,125 & \mu 1 & \text { (Applied Biosystems, Darmstadt) } \\ \text { Total } & \overline{4} & \mu 1 & \\ \text { + DNA } & 1 & \mu l & \end{array}$


Je $4 \mu \mathrm{l}$ Master Mix wurden in eine Vertiefung der 384 Well TaqMan Platte pipettiert und danach jeweils $1 \mu \mathrm{l}$ der zu untersuchenden DNA hinzugegeben. Es erfolgte außerdem eine Negativkontrolle mit $1 \mu \mathrm{H}_{2} \mathrm{O}$ anstelle der DNA, um eine Kontamination des Master Mix mit DNA auszuschließen. Dann wurde die TaqMan Platte mit einer Folie überklebt, um zu verhindern, dass die Proben verdampfen. Diese wurde danach in den Thermal Cykler gestellt und bei $95{ }^{\circ} \mathrm{C}$ für 10 Minuten inkubiert. Anschließend folgte die Denaturierung bei $92{ }^{\circ} \mathrm{C}$ für 15 Sekunden. Das Annealing und Extending erfolgte bei $60^{\circ} \mathrm{C}$ für 90 Sekunden. Es wurden insgesamt 50 Wiederholungen durchgeführt, die aus den beiden letztgenannten Schritte Denaturierung und Annealing/ Extending bestanden. Nach Beendigung der 50 Zyklen der Real-Time-PCR erfolgte das Auslesen der Ergebnisse. Dafür muss zunächst die Folie auf der TaqMan Platte gegen eine optische Folie ausgetauscht werden. Die Auswertung erfolgte in einem TaqMan 7900 HT-Gerät, das die Verteilung der VIC- bzw. FAM-Sonden, die dem jeweiligen Allel zugeordnet werden können, anzeigt und somit eine Bestimmung des jeweiligen Genotyps jedes Patienten erlaubt.

Anschließend wurde die Allelverteilung auf Übereinstimmung mit dem HardyWeinberg-Gesetz überprüft. Mit Hilfe des Hardy-Weinberg-Gesetzes lässt sich die Häufigkeit eines Allels in einer Population berechnen. Voraussetzung dafür ist, dass die Häufigkeiten der Genotypen bekannt sind. Im Gegenzug lässt sich auch die Häufigkeit eines Genotyps berechnen, sofern die Allelfrequenz bekannt ist. Ursprünglich gingen die Erfinder der Formel, Hardy und Weinberg, von einer „idealen Population“ aus, auf die sich ihre Formel anwenden ließ. Kennzeichen dieser idealen Population sind eine sehr große Individuenzahl, Panmixie (alle Paarungen, auch von Trägern verschiedener Genotypen, sind gleich wahrscheinlich und gleich erfolgreich) sowie fehlende Mutationen, Selektion oder Migration, die die Allelfrequenz ändern könnte.

Trotz des theoretischen Konstrukts der idealen Population lassen sich die Formeln durchaus mit Erfolg in der Praxis einsetzen.

Die Formeln lauten:

$\mathrm{p}+\mathrm{q}=1$

$p^{2}+2 p q+q^{2}=1$ 
Dabei repräsentiert $\mathrm{p}$ das eine (dominante) Allel und $\mathrm{q}$ das andere (rezessive) Allel. $\mathrm{p}^{2}$ entspricht dann der Häufigkeit des homozygoten Genotyps für das dominante Allel, 2pq der Häufigkeit des heterozygoten Genotyps und $\mathrm{q}^{2}$ dementsprechend der Häufigkeit des homozygoten Genotyps für das rezessive Allel.

\subsection{Statistische Analyse}

Alle statistischen Analysen wurden mithilfe von SPSS für Windows (SPSS Inc. Chicago, USA) durchgeführt. Kontinuierliche Variablen wurden als Mittelwert \pm SD (Standardabweichung) ausgedrückt, kategorische Variablen als absolute Zahlen oder Prozentangabe. Bevor die statistische Analyse durchgeführt wurde, wurden die Daten auf Normalverteilung überprüft. Die peri- und postoperativen Daten wurden für kategorial skalierte Daten mit dem Chi-Quadrat- $\left(\chi^{2}-\right)$ Test nach Pearson und für ordinal skalierte Daten mit dem Kruskal-Wallis-Test untersucht. Peri- und postoperative Risikofaktoren wurden dem multivariaten Modell zugefügt, wenn sie in der univariaten Analyse als signifikant identifiziert worden waren. Die multivariate logistische Regressionsanalyse wurde durchgeführt, um den unabhängigen Effekt dieser Risikofaktoren auf die Notwendigkeit einer postoperativen Nierenersatztherapie zu untersuchen.

Die Allelfrequenzen in der Studienpopulation wurden ausgezählt, mit der erwarteten Verteilung in der Normalpopulation nach der Hardy-Weinberg-Regel verglichen und mit dem $\chi^{2}$-Test überprüft.

Signifikanz wurde angenommen ab einem $p$-Wert von $<0,05$ für die univariate Analyse, bzw. ab einem $p$-Wert von $<0,0001$ für die multivariate Analyse. 


\section{Ergebnisse}

\subsection{Häufigkeitsverteilung der Allele}

Mittels der Untersuchung der Patienten-DNA mit Real-Time-PCR konnte von 481 Patienten der EPO-SNP-rs1617640-Genotyp bestimmt werden. Entsprechend ihres Genotyps wurden die Probanden dann in drei Gruppen eingeteilt: Homozygote Träger des T-Allels (TT), heterozygote Allelträger mit dem Genotyp TG und homozygote Träger des G-Allels (GG). Dabei zeigte sich folgendes Verteilungsmuster: Von den 481 Patienten fielen 172 (35,8 \%) in die Gruppe mit den Allelen TT, 234 (48,6 \%) in die Gruppe der heterozygoten Allelträger TG und 75 (15,6 \%) gehörten der Gruppe der GG- Allelträger an. Für das Risikoallel TT wurde gezeigt, dass es mit erhöhten EPOKonzentrationen im Blut einhergeht, und dass ein Zusammenhang mit PDR und ESRD bei Patienten mit Diabetes mellitus besteht.

Die beobachteten Ergebnisse entsprechen der erwarteten Allelverteilung des EPO-SNP-rs1617640-Polymorphismus in der Population nach Hardy-Weinberg $(p=0,946)$ (Tab. 2). Sie zeigte sich außerdem vergleichbar mit der beobachteten Allelverteilung einer bereits veröffentlichten Studie (Tong et al. 2008).

Tabelle 2: Allelverteilung

\begin{tabular}{cccccc}
\hline rs1617640 & TT & TG & GG & T-Allel & C-Allel \\
\hline \hline $\mathrm{n}=481$ & $172(35,8 \%)$ & $234(48,6 \%)$ & $75(15,6 \%)$ & $578(60,1 \%)$ & $384(39,9 \%)$ \\
\hline
\end{tabular}

\subsection{Vergleich der klinischen und demographischen Daten}

Die allgemeinen und präoperativen Daten aller Patienten sind angeordnet nach ihrem Genotyp in Tabelle 3 zusammengefasst. Es fanden sich keine signifikanten Unterschiede zwischen den Gruppen bezüglich Geschlecht, Alter und Body Mass Index 
(BMI). Untersuchte Risikofaktoren wie Rauchen, Hypertonus, Hypercholesterinämie, Diabetes mellitus, positive Familienanamnese, Ejektionsfraktion, periphere arterielle Verschlusskrankheit (PAVK), cerebrale Ereignisse in der Vorgeschichte, chronisch obstruktive Lungenerkrankung (COPD) und pulmonaler Hypertonus ergaben ebenfalls keinen signifikanten Unterschied.

Präoperativ wurden außerdem bei allen Patienten die Nierenfunktionsparameter Kreatinin, Kreatinin- Clearance (berechnet nach der Formel von Cockroft und Gault) und Hämatokrit bestimmt. Hier ließ sich kein signifikanter Unterschied zwischen den Gruppen erkennen. Hingegen fand sich eine präoperative renale Dysfunktion signifikant häufiger in der TT- Allelgruppe $(p=0,03)$. 
Tabelle 3: Klinische und demographische Verteilung

\begin{tabular}{|c|c|c|c|c|}
\hline Variable & $\begin{array}{c}\text { TT } \\
n=172\end{array}$ & $\begin{array}{c}\text { TG } \\
n=234\end{array}$ & $\begin{array}{c}\text { GG } \\
n=75\end{array}$ & $p$-Wert \\
\hline Alter (Jahre) & $68,7 \pm 9,9$ & $66,3 \pm 11,0$ & $66,9 \pm 10,6$ & 0,08 \\
\hline Geschlecht (m/w) & $\begin{array}{c}107(62,2 \%) / \\
65(37,8 \%)\end{array}$ & $\begin{array}{c}155(66,2 \%) / \\
79(33,8 \%)\end{array}$ & $\begin{array}{l}46(61,3 \%) / \\
29(38,7 \%)\end{array}$ & 0,58 \\
\hline \multicolumn{5}{|l|}{ Risikofaktoren } \\
\hline Body mass index $\left(\mathrm{kg} / \mathrm{m}^{2}\right)$ & $28,2 \pm 13,8$ & $27,9 \pm 4,8$ & $27,2 \pm 4,0$ & 0,69 \\
\hline Rauchen & $60(34,9 \%)$ & $82(35,0 \%)$ & $25(33,3 \%)$ & 0,94 \\
\hline Hypertonus & $124(72,1 \%)$ & $169(72,2 \%)$ & $57(76,0 \%)$ & 0,84 \\
\hline Hypercholesterinämie & $82(47,7 \%)$ & $116(49,6 \%)$ & $32(42,7 \%)$ & 0,56 \\
\hline Diabetes mellitus & $65(37,8 \%)$ & $64(27,4 \%)$ & $21(28,0 \%)$ & 0,06 \\
\hline Positive Familienanamnese & $36(20,9 \%)$ & $37(15,9 \%)$ & $8(10,7 \%)$ & 0,11 \\
\hline Ejektionsfraktion & $53 \pm 14$ & $54 \pm 14$ & $53 \pm 14$ & 0,75 \\
\hline PAVK & $15(8,7 \%)$ & $15(6,4 \%)$ & $6(8,0 \%)$ & 0,66 \\
\hline Zerebrale Ereignisse & $20(11,6 \%)$ & $34(14,5 \%)$ & $10(13,3 \%)$ & 0,72 \\
\hline Pulmonaler Hypertonus & $10(5,8 \%)$ & $19(8,1 \%)$ & $9(12,0 \%)$ & 0,26 \\
\hline COPD & $15(8,7 \%)$ & $15(6,4 \%)$ & $9(12,0 \%)$ & 0,29 \\
\hline Renale Dysfunktion & $33(19,2 \%)$ & $24(10,2 \%)$ & $9(12,0 \%)$ & 0,03 \\
\hline \multicolumn{5}{|l|}{ Nierenfunktionsparameter } \\
\hline Serum Kreatinin (mg/dl) & $1,3 \pm 1$ & $1,1 \pm 0,5$ & $1,1 \pm 0,6$ & 0,08 \\
\hline Serum Harnstoff (mg/dl) & $23 \pm 14$ & $20 \pm 11$ & $23 \pm 16$ & 0,11 \\
\hline Kreatinin-clearance (ml/min) & $74 \pm 34$ & $78 \pm 33$ & $74 \pm 30$ & 0,55 \\
\hline Hämatokrit (\%) & $40 \pm 6$ & $40 \pm 5$ & $39 \pm 5$ & 0,32 \\
\hline
\end{tabular}

Positive Familienanamnese $=$ KHK oder stattgehabter Myokardinfarkt bei

\section{Verwandten 1. Grades}

PAVK = Periphere arterielle Verschlusskrankheit

Zerebrale Ereignisse $=$ Apoplex, transitorisch ischämische Attacken (TIA), prolongierte reversible Ischämie mit neurologischem Defizit (PRIND)

COPD = Chronisch obstruktive Lungenerkrankung

Renale Dysfunktion = anamnestisch Serum-Kreatininwerte von $>1,5 \mathrm{mg} / \mathrm{dl}$ 
Im Rahmen der Studie wurde außerdem der präoperative Einsatz bestimmter Medikamente innerhalb der Gruppen untersucht (Tabelle 4). Dabei ergab sich ein signifikant höherer Einsatz von Antiarrhythmika $(p=0,04)$ in der TT-Gruppe. Bei allen anderen untersuchten Vormedikationen zeigte sich dagegen kein signifikanter Unterschied.

Tabelle 4: Präoperative Medikation

\begin{tabular}{lcccc}
\hline Variable & $\begin{array}{c}\text { TT } \\
\mathbf{n}=\mathbf{1 7 2}\end{array}$ & $\begin{array}{c}\text { TG } \\
\mathbf{n}=\mathbf{2 3 4}\end{array}$ & $\begin{array}{c}\text { GG } \\
\mathbf{n}=\mathbf{7 5}\end{array}$ & $\boldsymbol{p}$-Wert \\
\hline \hline B-Blocker & $109(63,4 \%)$ & $155(66,2 \%)$ & $45(60,0 \%)$ & 0,58 \\
ACE-Hemmer & $84(48,8 \%)$ & $133(56,8 \%)$ & $42(56,0 \%)$ & 0,31 \\
Orale Nitrate & $31(18,0 \%)$ & $37(15,8 \%)$ & $19(25,3 \%)$ & 0,18 \\
Antiarrhythmika & $12(7,0 \%)$ & $5(2,1 \%)$ & $2(2,7 \%)$ & $\mathbf{0 , 0 4}$ \\
Diuretika & $69(40,1 \%)$ & $90(38,5 \%)$ & $34(45,3 \%)$ & 0,59 \\
Lipidsenker & $88(51,2 \%)$ & $112(47,9 \%)$ & $32(42,7 \%)$ & 0,41 \\
Antidiabetika & $42(24,4 \%)$ & $38(16,2 \%)$ & $14(18,7 \%)$ & 0,11 \\
Andere Antihypertensiva & $44(25,6 \%)$ & $52(22,2 \%)$ & $11(14,7 \%)$ & 0,15 \\
Bronchodilatatoren & $6(3,5 \%)$ & $5(2,1 \%)$ & $2(2,7 \%)$ & 0,70 \\
Antikoagulanzien & $123(71,5 \%)$ & $156(66,7 \%)$ & $51(68,0 \%)$ & 0,50 \\
\hline
\end{tabular}


Bei der Dringlichkeit der Operation (Notfall) ließ sich kein signifikanter Unterschied zwischen den Gruppen feststellen. Bezüglich der Art der Operation, der Aortenklemmzeit sowie der Dauer des Anschlusses an die Herz-Lungen-Maschine (HLM) konnte ebenfalls kein signifikanter Unterschied ermittelt werden. Die operativen Parameter sind in Tabelle 5 festgehalten.

Tabelle 5: Operationsassoziierte Parameter

\begin{tabular}{|c|c|c|c|c|}
\hline Variable & $\begin{array}{c}\text { TT } \\
n=172\end{array}$ & $\begin{array}{c}\text { TG } \\
n=234\end{array}$ & $\begin{array}{c}\text { GG } \\
n=75\end{array}$ & $p$-Wert \\
\hline \multicolumn{5}{|l|}{ Dringlichkeit der Operation } \\
\hline Notfall $(n=41)$ & $12(7,0 \%)$ & $25(10,7 \%)$ & $4(5,3 \%)$ & 0,17 \\
\hline \multicolumn{5}{|l|}{ Operativer Eingriff } \\
\hline Koronararterieller Bypass $(n=246)$ & $99(57,6 \%)$ & $106(45,3 \%)$ & $41(54,7 \%)$ & 0,11 \\
\hline Herzklappenoperation ( $n=100)$ & $34(19,8 \%)$ & $51(21,8 \%)$ & $15(20,0 \%)$ & 0,80 \\
\hline Kombinierte Verfahren $(n=120)$ & $38(22,1 \%)$ & $64(27,4 \%)$ & $18(24,0 \%)$ & 0,14 \\
\hline Andere Eingriffe $(n=15)$ & $3(1,7 \%)$ & $8(3,4 \%)$ & $4(5,3 \%)$ & 0,15 \\
\hline \multicolumn{5}{|l|}{ Perioperative Charakteristika } \\
\hline Aortenklemmzeit (min) & $92,4 \pm 36,4$ & $96,9 \pm 37,9$ & $92,6 \pm 44,9$ & 0,24 \\
\hline HLM-Zeit (min) & $142 \pm 75,3$ & $144 \pm 55$ & $155 \pm 88$ & 0,41 \\
\hline Euroscore additive & $6 \pm 3,9$ & $6 \pm 3,8$ & $5 \pm 3,8$ & 0,64 \\
\hline
\end{tabular}




\subsection{Perioperative Parameter}

Nach der Operation wurden die Patienten auf der Intensivstation überwacht. Während der ersten 24 Stunden wurden unterschiedliche Parameter untersucht und innerhalb der Gruppen verglichen (Tabelle 6). Bei den Untersuchungen der hämodynamischen Parameter zeigten sich keine signifikanten Unterschiede zwischen den Gruppen.

Tabelle 6: Perioperative Parameter: Hämodynamik

\begin{tabular}{lcccc}
\hline Variable & $\begin{array}{c}\mathrm{TT} \\
\mathbf{n}=\mathbf{1 7 2}\end{array}$ & $\begin{array}{c}\text { TG } \\
\mathbf{n}=\mathbf{2 3 4}\end{array}$ & $\begin{array}{c}\mathbf{G G} \\
\mathbf{n = 7 5}\end{array}$ & $\boldsymbol{p}$-Wert \\
\hline \hline Hämodynamik & & & & \\
Herzfrequenz (1/min) & $82 \pm 14$ & $81 \pm 12$ & $84 \pm 14$ & 0,30 \\
MAP (mmHg) & $80 \pm 9$ & $80 \pm 8$ & $80 \pm 8$ & 0,98 \\
ZVD (mmHg) & $11 \pm 3$ & $11 \pm 4$ & $12 \pm 3$ & 0,10 \\
PCWP (mmHg) & $15 \pm 4$ & $14 \pm 5$ & $14 \pm 4$ & 0,64 \\
PAP mean (mmHg) & $25 \pm 5$ & $25 \pm 5$ & $28 \pm 14$ & 0,94 \\
Cl (I/min/m $)$ & $4 \pm 3$ & $3 \pm 1$ & $3 \pm 1$ & 0,30 \\
SVRI (dyn-s-1.m².cm-5) & $884 \pm 189$ & $1017 \pm 469$ & $1016 \pm 464$ & 0,67 \\
PVRI (dyn-s-1.m².cm-5) & $208 \pm 143$ & $222 \pm 198$ & $182 \pm 98$ & 0,78 \\
\hline
\end{tabular}

MAP $=$ Mean arterial pressure (Mittlerer arterieller Druck)

ZVD $=$ Zentraler Venendruck

PCWP = Pulmonary capillary wedge pressure

(Pulmonalarterienverschlussdruck)

PAP $=$ Pulmonary arterial pressure (Pulmonal-arterieller Druck)

$\mathrm{Cl}=$ Cardiac Index (Herzindex)

SVRI = Systemic vascular resistance index

(Systemischer Gefäßwiderstandsindex)

$\mathrm{PVRI}=$ Pulmonary vascular resistance index

(Pulmonaler Gefäßwiderstandsindex) 
In Tabelle 7 wird dargestellt, wie der Medikamentenbedarf postoperativ innerhalb der ersten 24 Stunden war. Bei der Anwendung von Inotropika zeigte sich kein signifikanter Unterschied bei den Medikamenten zwischen den Gruppen, obwohl die Anwendung von Epinephrin $(\mathrm{TT}=51 \pm 29 ; \mathrm{TG}=7 \pm 22 ; \mathrm{GG}=6 \pm 10)$ und Enoximon $(\mathrm{TT}=467 \pm 681$; $\mathrm{TG}=259 \pm 320 ; \mathrm{GG}=234 \pm 257$ ) in der TT-Genotyp-Gruppe höher war. Bei den anderen untersuchten Medikamenten (Nitroglycerin, Amiodaron und Kortison) zeigte sich ebenfalls kein signifikanter Unterschied.

Tabelle 7: Perioperative Parameter: Angewandte Medikamente

\begin{tabular}{lcccc}
\hline Variable & $\begin{array}{c}\text { TT } \\
\mathbf{n}=\mathbf{1 7 2}\end{array}$ & $\begin{array}{c}\text { TG } \\
\mathbf{n}=\mathbf{2 3 4}\end{array}$ & $\begin{array}{c}\text { GG } \\
\mathbf{n}=\mathbf{7 5}\end{array}$ & $\mathbf{p}$-Wert \\
\hline \hline Inotropika & & & & \\
Epinephrin (mg/d) & $51 \pm 29$ & $7 \pm 22$ & $6 \pm 10$ & 0,62 \\
Norepinephrin (mg/d) & $9 \pm 14$ & $12 \pm 32$ & $8 \pm 18$ & 0,96 \\
Levosimendan (mg/d) & $9 \pm 3$ & 0 & $4 \pm 0$ & 1,0 \\
Enoximon (mg/d) & $467 \pm 681$ & $259 \pm 320$ & $234 \pm 257$ & 0,56 \\
Dobutamin (mg/d) & $169 \pm 142$ & $182 \pm 170$ & $162 \pm 112$ & 0,99 \\
Andere & & & & \\
Nitroglycerin (mg/d) & $24 \pm 39$ & $28 \pm 43$ & $21 \pm 19$ & 0,80 \\
Amiodaron (mg/d) & $624 \pm 542$ & $733 \pm 629$ & $772 \pm 657$ & 0,98 \\
Kortison (mg/d) & $474 \pm 753$ & $878 \pm 1309$ & $772 \pm 657$ & 0,43 \\
\hline
\end{tabular}

Die Untersuchung der Nierenfunktionsparameter ergab einen signifikanten Unterscheid zwischen den Genotypen bezüglich der Notwendigkeit einer Nierenersatztherapie $(p=0,03)$ und eines Anstiegs der Kreatinphosphokinase-MB $(p=0,03)$ in der TT-Gruppe. Bei den anderen untersuchten Nierenfunktionsparametern (Serumkreatinin max, Serumkreatinin-Anstieg, Kreatinin-Clearance min, Veränderung der Kreatinin-Clearance, Hämatokrit und Furosemid) zeigte sich kein Unterschied zwischen den Gruppen. Auch bei den untersuchten Scores (RIFLE, ARF, APACHE II (Acute physiology and chronic health evaluation II Score) und SAPS II (Simplified acute physiology II Score)) ließ sich kein signifikanter Unterschied zwischen den unterschiedlichen Genotypen ermitteln. Alle genannten Ergebnisse finden sich in Tabelle 8 aufgelistet. 
Tabelle 8: Perioperative Parameter: Nierenfunktion und Scores

\begin{tabular}{|c|c|c|c|c|}
\hline Variable & $\begin{array}{c}\text { TT } \\
n=172\end{array}$ & $\begin{array}{c}\text { TG } \\
n=234\end{array}$ & $\begin{array}{c}\text { GG } \\
n=75\end{array}$ & $p$-Wert \\
\hline \multicolumn{5}{|l|}{ Nierenfunktion } \\
\hline Serumkreatinin max $(\mathrm{mg} / \mathrm{dl})$ & $1,9 \pm 1,3$ & $1,9 \pm 3,6$ & $1,8 \pm 1,3$ & 0,14 \\
\hline Serumkreatinin-Anstieg (\%) & $75 \pm 129$ & $70 \pm 177$ & $73 \pm 128$ & 0,75 \\
\hline Kreatinin- Clearance $\min (\mathrm{ml} / \mathrm{min})$ & $54 \pm 33$ & $60 \pm 33$ & $59 \pm 33$ & 0,11 \\
\hline $\begin{array}{l}\text { Veränderung Kreatinin- } \\
\text { Clearance }(\mathrm{ml} / \mathrm{min})\end{array}$ & $20 \pm 37$ & $17 \pm 41$ & $14 \pm 41$ & 0,80 \\
\hline Hämatokrit min (\%) & $27 \pm 3$ & $27 \pm 4$ & $27 \pm 4$ & 0,87 \\
\hline Harnstoff $\max (\mathrm{ml} / \mathrm{dl})$ & $40 \pm 26$ & $40 \pm 35$ & $46 \pm 79$ & 0,43 \\
\hline Furosemid gesamt (mg) & $99 \pm 166$ & $85 \pm 123$ & $85 \pm 125$ & 0,91 \\
\hline S-CPK (U/l) & $1033 \pm 1473$ & $970 \pm 1948$ & $1006 \pm 1923$ & 0,10 \\
\hline S-CPK-MB (U/I) & $52 \pm 70$ & $42 \pm 53$ & $43 \pm 60$ & 0,03 \\
\hline Kalium & $4,6 \pm 0,5$ & $4,6 \pm 0,5$ & $4,6 \pm 0,6$ & 0,53 \\
\hline Laktat & $1,8 \pm 2,2$ & $1,4 \pm 1,3$ & $1,5 \pm 1$ & 0,21 \\
\hline $\mathrm{CVVH}$ & $20(11,6 \%)$ & $11(4,7 \%)$ & $7(9,3 \%)$ & 0,03 \\
\hline \multicolumn{5}{|l|}{ Scores } \\
\hline \multicolumn{5}{|l|}{$\begin{array}{l}\text { Rifle Score (1. Tag postoperativ) } \\
(n=274)\end{array}$} \\
\hline $\mathrm{R}$ (Risk) $\quad \mathrm{n}=60$ & $20(11,6 \%)$ & $32(13,7 \%)$ & $8(10,7 \%)$ & 0,87 \\
\hline I (Injury) n=62 & $23(13,4 \%)$ & $29(12,4 \%)$ & $10(13,3 \%)$ & 0,95 \\
\hline F (Failure) $n=152$ & $62(36,0 \%)$ & $71(30,3 \%)$ & $19(25,3 \%)$ & 0,82 \\
\hline ARF Score & $5 \pm 2$ & $5 \pm 2$ & $5 \pm 2$ & 0,14 \\
\hline APACHE II Score & $15,3 \pm 6,6$ & $14,8 \pm 6,6$ & $15,5 \pm 6,4$ & 0,44 \\
\hline SAPS II Score & $25 \pm 8$ & $24,4 \pm 6,2$ & $25,1 \pm 9,1$ & 0,57 \\
\hline
\end{tabular}

S-CPK = Serum-Kreatinphosphokinase

S-CPK-MB = Serum-Kreatinphosphokinase-Muscle Brain

$\mathrm{CVVH}=$ kontinuierliche veno-venöse Hämofiltration (Nierenersatztherapie)

ARF = Acute Renal Failure Score

APACHE II = Acute physiology and chronic health evaluation II Score

SAPS II = Simplified acute physiology II Score 


\subsection{Postoperative Parameter}

Wie in Tabelle 9 dargestellt, konnte kein Zusammenhang zwischen der Notwendigkeit der Anwendung von Erythrozytenkonzentraten (EKs), gefrorenen Frischplasmen oder Prothrombinkomplex-Konzentraten (PPSBs) und dem jeweiligen Genotyp festgestellt werden.

Vergleichbar waren außerdem die Werte einer extrakorporalen Membranoxygenierung (ECMO) zwischen den Gruppen. Ein Unterschied zeigte sich dagegen bezüglich des Einsatzes einer intraaortalen Ballonpumpe (IABP).

Es fand sich keine Korrelation zwischen dem Genotyp und der Dauer des Aufenthaltes auf der Intensivstation, des gesamten Krankenhausaufenthaltes und Mortalität im Krankenhaus.

Tabelle 9: Postoperative Parameter

\begin{tabular}{|c|c|c|c|c|}
\hline Variable & $\begin{array}{c}\mathrm{TT} \\
\mathrm{n}=172\end{array}$ & $\begin{array}{c}\text { TG } \\
n=234\end{array}$ & $\begin{array}{c}\text { GG } \\
n=75\end{array}$ & $p$-Wert \\
\hline \multicolumn{5}{|l|}{ Erythrozytenkonzentrate (ml/d) } \\
\hline innerhalb der ersten 24 Stunden & $286 \pm 785$ & $214 \pm 457$ & $295 \pm 679$ & 0,68 \\
\hline \multicolumn{5}{|l|}{ Gefrorene Frischplasmen (ml/d) } \\
\hline innerhalb der ersten 24 Stunden & $97 \pm 775$ & $54 \pm 273$ & $104 \pm 534$ & 0,92 \\
\hline PPSB & $46 \pm 375$ & $4 \pm 65$ & 0 & 0,24 \\
\hline IABP & $19(11,0 \%)$ & $15(6,4 \%)$ & $1(1,3 \%)$ & 0,02 \\
\hline ECMO & 0 & $1(0,4 \%)$ & 0 & 0,59 \\
\hline $\begin{array}{l}\text { Aufenthalt auf der Intensivstation } \\
\text { (in Tagen) }\end{array}$ & $6 \pm 10,8$ & $8,3 \pm 14,5$ & $11,3 \pm 20,9$ & 0,16 \\
\hline $\begin{array}{l}\text { Krankenhausaufenthalt } \\
\text { (in Tagen) }\end{array}$ & $23 \pm 14,7$ & $25,1 \pm 21,3$ & $30,4 \pm 25,7$ & 0,30 \\
\hline \multicolumn{5}{|l|}{ Mortalität } \\
\hline Tod im Krankenhaus (\%) $n=40$ & $16(9,3 \%)$ & $15(6,4 \%)$ & $9(12,0 \%)$ & 0,26 \\
\hline
\end{tabular}




\subsection{Multivariate Analyse}

Alle mithilfe der univariaten Analyse als statistisch signifikant identifizierten peri- und postoperativen Risikofaktoren wurden in eine multivariate logistische Regressionsanalyse eingefügt. Der folgende Faktor konnte als unabhängiger Risikofaktor identifiziert werden: S-CPK-MB (Odds Ratio: 1,0114 (95 \% CI: 1,0082 bis $1,0207, p=<0,0001))$.

Die anderen statistisch signifikanten peri- und postoperativen Risikofaktoren wie die renale Dysfunktion (Odds Ratio: 3,25 (95 \% CI: 1,3865 bis 7,6183, $p=0,0677$ ) und die Benutzung einer IABP (Odds Ratio: 5,0626 (95 \% CI: 1,9710 bis 13,0035, $p=0,0008)$ ) waren nicht unabhängig. 


\section{Diskussion}

Ziel dieser Studie war es herauszufinden, ob das T-Allel von SNP-rs1617640 in der Promotorregion des EPO-Gens einen Einfluss auf die postoperative Nierenfunktion bei am Herzen operierten Patienten mit Einsatz einer Herz-Lungen-Maschine hat. Mit Hilfe der RIFLE- und AKIN-Scores und nierenspezifischer Laborparameter wurde sowohl auf das Auftreten eines akuten Nierenversagens untersucht als auch auf die Schwere der Nierenschädigung, sofern diese auftrat. Dabei wurde ein besonderes Augenmerk darauf gelegt, ob postoperativ ein Unterschied zwischen den homozygoten TT-Allelträgern im Vergleich zu den anderen Genotypen (GT und GG) bestand.

Eine postoperative Nierenfunktionsstörung ist eine relativ häufige und schwere Komplikation nach einer Herzoperation. So kann man davon ausgehen, dass von weltweit allen Patienten, die sich einer elektiven Bypass-Operation mit Herz-LungenMaschine unterziehen, etwa $8 \%$ ein perioperatives akutes Nierenversagen erleiden, das bei bis zu $1 \%$ mit einer Dialysepflichtigkeit einhergeht (Chertow et al. 1997; Conlon et al. 1999; Mangano et al. 1998; Roach et al. 1996). Die Ätiologie einer Nierenfunktionsstörung nach Herzoperation ist multifaktoriell und schon geringe Ausprägungen einer postoperativen Nierenschädigung sind mit einer deutlich erhöhten Morbiditäts- und Mortalitätsrate assoziiert. Sofern ein Nierenversagen so schwer ist, dass eine Nierenersatztherapie erforderlich wird, kann die Mortalitätsrate auf bis zu $63 \%$ steigen (Chertow et al. 1998; Mangano et al. 1998).

Es konnten bereits mehrere Genpolymorphismen identifiziert werden, die mit einem akuten Nierenversagen nach Herzoperation assoziiert sind. Im Jahr 2005 untersuchten Stafford-Smith und Mitarbeiter in einer Studie 1768 Patienten, die sich einer elektiven aorto-koronaren Bypassoperation mit HLM unterzogen, auf das Auftreten eines postoperativen Nierenvesagens und testeten die Patienten auf mehrere Polymorphismen. Mithilfe der Bestimmung verschiedener Nierenfunktionsparameter konnten sie zeigen, dass insbesondere die Kombination von 2 Genpolymorphismen (beispielsweise AGT-842C und IL6-572C) mit erhöhten postoperativen KreatininWerten assoziiert ist. Bei dieser Genkombination konnten sie erhöhte Entzündungswerte sowie Endotoxinspiegel im Blut nachweisen, welche mit einer Nierenschädigung im Zusammenhang stehen können. Ferner konnten sie aufzeigen, 
dass besonders Genpolymorphismen, die mit einer vermehrten Vasokonstriktion in Verbindung gebracht werden, ein erhöhtes Risiko für eine postoperative Nierenschädigung mit sich bringen. Unter der Vasokonstriktion wird die Durchblutung der Niere verringert, was zu einer Schädigung des Organs führen kann. Aus diesen Beobachtungen lässt sich schließen, dass sowohl das Vorliegen von Entzündungsmediatoren, als auch von vasokonstriktorisch wirksamen Substanzen die Wahrscheinlichkeit des Auftretens einer Nierenschädigung erhöhen. Die Ursache für eine solche erhöhte Entzündungsreaktionen in der Niere und/ oder erhöhte vasokonstriktorische Impulse kann das Vorliegen bestimmter Genvariationen sein. Weiterhin konnte in der Studie gezeigt werden, dass die Untersuchung von Genpolymorphismen in Kombination mit klinischen Parametern der alleinigen Untersuchung klinischer Parameter überlegen ist (Stafford-Smith et al. 2005).

Popov et al. identifizierten 2009 einen weiteren Polymorphismus, der mit einem postoperativen Nierenversagen assoziiert ist. Sie untersuchten 497 Patienten, die sich einer Herzoperation mit Anschluss an die HLM unterzogen, auf das Auftreten eines postoperativen Nierenversagens. Der Polymorphismus, den sie untersuchten, ist der eNOS-T-786C-Polymorphismus im Bereich des Promotors des eNOS-Gens, für den bereits in anderen Studien eine Assoziation mit der Verschlechterung der Hämodynamik und dem Auftreten einer koronaren Herzerkrankung festgestellt werden konnte. In ihrer Studie konnte gezeigt werden, dass in der Risikogruppe der CAllelträger ein signifikant erhöhter Bedarf einer Nierenersatztherapie bestand sowie eine geringere minimale Kreatinin-Clearance und ein stärkerer postoperativer Abfall der Kreatinin-Clearance (Popov et al. 2009). Aufgrund der Tatsache, dass bei CAllelträgern eine verminderte Transkription der eNOS vorliegt und somit eine geringere Konzentration des Vasodilatators NO im Blut nachzuweisen ist, deckt sich diese Beobachtung mit denen von Stafford-Smith et al., die ebenfalls eine verstärkte Vasokonstriktion mit einer postoperativen Nierenschädigung in Verbindung brachten.

Karadag und Mitarbeiter zeigten 2009 in einer Studie, dass die Administration von EPO mit einer Erhöhung des Endothelin 1 (ET1)-Levels im Blut einhergeht (Karadag et al. 2009). Endothelin 1 ist ein potenter Vasokonstriktor und wirkt im gesamten Körper. Folglich kann es durch eine Steigerung der ET1-Konzentration auch zu einer Vasokonstriktion im Bereich der Nierenarterie kommen und somit zu einer Minderdurchblutung der Niere führen. Ishikawa et al. zeigten schon 1999, dass der renale Blutfluss durch die Gabe von rHuEPO signifikant vermindert wird. Auch sie 
nahmen an, dass es sich bei dem Mediator dieses Effekts um ET1 handelt, da sein Level unter EPO-Gabe deutlich ansteigt. Sie unterstützten diese Hypothese, indem sie in ihrer Studie zeigten, dass bei zusätzlicher Verabreichung des ET1-Antagonisten S-0139 zur EPO-Gabe der renale Blutfluss nicht vermindert war (Ishikawa et al. 1999).

Es lässt sich aus diesen Ergebnissen also schlussfolgern, dass beim Risikoallel TT des EPO-SNP-rs1617640 Polymorphismus aufgrund der erhöhten EPOKonzentration auch eine vermehrte Vasokonstriktion der Nierenarterie resultieren könnte. Eine solche Vasokonstriktion und die daraus folgende verminderte Nierendurchblutung ist bereits in mehreren Studien als Risikofaktor für ein postoperatives Nierenversagen identifiziert worden.

Trotz des Wissens über den Einfluss von Genpolymorphismen bleiben die Möglichkeiten, mit ihrer Hilfe die Wahrscheinlichkeit und die Schwere einer Niereninsuffizienz vorherzusehen, begrenzt, da präoperative klinische, verfahrensassoziierte und biologische Marker nur eine begrenzte Aussagekraft haben.

Wie bereits erwähnt, geht man außerdem davon aus, dass Entzündungsreaktionen eine wichtige Rolle bei der Entwicklung eines postoperativen Nierenversagens spielen, da im Rahmen einer Herzoperation viele Stimuli vorliegen, die eine solche Reaktion auslösen können. Dazu gehören beispielsweise die extrakorporale Zirkulation durch die Herz-Lungen-Maschine, Endotoxine und Endothelschädigungen (Martinez-Pellus et al. 1997; Tonnesen et al. 1996). Es ist bekannt, dass eine extrakorporale Zirkulation wie beim Anschluss an die Herz- LungenMaschine mit einer multiplen Störung der renalen Physiologie und Funktion assoziiert ist (siehe Kapitel 1.2.5). Es kommt $\mathrm{zu}$ einer vermehrten Freisetzung von Entzündungsmediatoren im Körper, die zu Schädigungen der Niere führen können. Zu den Auswirkungen zählen eine Verminderung des renalen Blutflusses und der GFR sowie ein Anstieg des renalen Gefäßwiderstandes, resultierend in einer Verschlechterung der Nierenfunktion.

Anlass für die Untersuchung des EPO-SNP-rs1617640-Polymorphismus war eine Studie von Tong und Mitarbeitern, die 2008 zeigen konnten, dass das T-Allel von SNP-rs1617640 im Promotor des EPO-Gens mit dem vermehrten Auftreten von proliferativer diabetischer Retinopathie (PDR) und terminaler Niereninsuffizienz $(\mathrm{ESRD}=\mathrm{end}$ stage renal disease) assoziiert ist. Als weiteren interessanten Befund konnten sie nachweisen, dass die EPO-Konzentration im menschlichen Körper bei Trägern des risikoassoziierten TT-Allels 7,5mal höher war als bei GG-Allelträgern. In 
ihrer Studie untersuchten sie mehrere Kohorten (europäisch-amerikanisch) mit Diabetes mellitus und den Komplikationen einer PDR und ESRD. Sie testeten auf 19 unterschiedliche Genpolymorphismen und verglichen die Ergebnisse mit denen einer Kontrollgruppe aus Individuen mit Diabetes mellitus, aber ohne die beiden genannten Komplikationen. Dabei wurden sowohl Patienten mit Diabetes mellitus Typ 1 als auch Typ 2 in unterschiedlichen Kohorten untersucht. Ein signifikanter Zusammenhang konnte nur beim EPO-SNP-rs1617640-Polymorphismus gefunden werden; dieser bestätigte sich aber sowohl bei denen an Diabetes mellitus Typ 1 als auch an Typ 2 erkrankten untersuchten Individuen und für beide untersuchten Komplikationen.

Die Ergebnisse dieser Studie zeigen einen Befund, der sich damit vereinbaren lässt. Es zeigte sich, dass der EPO-SNP-rs1617640-Polymorphismus einen Einfluss auf den Bedarf einer postoperativen Nierenersatztherapie hat. Eine Dialysepflichtigkeit war in der Gruppe der TT-Allelträger signifikant erhöht $(p=0,03)$. Es ist anzunehmen, dass bei diesen Patienten eine höhere Expression des Erythropoietins vorliegt und somit der EPO-Spiegel im Serum bei diesen Patienten erhöht ist. Diese Konzentrationserhöhung könnte eine Steigerung des Risikos für die Entwicklung eines akuten Nierenversagens mit der Notwendigkeit einer Nierenersatztherapie nach einer Herzoperation mit HerzLungen-Maschine bedingen.

Des Weiteren konnte in dieser Studie ein signifikanter Anstieg der Kreatinphosphokinase-MB (CPK-MB) $(p=0,03)$ zusätzlich zu der Notwendigkeit einer Nierenersatztherapie bei Individuen mit dem TT-Genotyp festgestellt werden. Der traditionelle Risikofaktor der präoperativen Niereninsuffizienz zeigt in der univariaten Analyse eine Assoziation mit homozygoten T-Allelträgern, allerdings zeigte sich in der multivariaten Analyse, dass dieser Risikofaktor nicht unabhängig zu sehen ist. Es wäre möglich, dass eine präoperative Nierenfunktionsstörung, welche häufiger in der TTGenotyp-Gruppe zu finden war $(p=0,03)$, einen Einfluss auf das Bedürfnis nach einer postoperativen Nierenersatztherapie hat. Es ist durchaus beschrieben, dass Patienten mit vorbestehender Niereninsuffizienz ein höheres Risiko besitzen, eine schwere nierenassoziierte Komplikation (z.B. Dialysepflichtigkeit) im Zusammenhang mit einer Herzoperation zu entwickeln (Anderson et al. 1999; Anderson et al. 2000; Rao et al. 1997). Andere Forschergruppen zeigten hingegen, dass das Vorliegen einer verminderten Nierenfunktion zum Zeitpunkt der Operation kein definitiver Prädiktor für das Risiko einer Nierenschädigung insgesamt ist und dass bei diesen Patienten kein erhöhtes Risiko für eine weitere Verschlechterung der Nierenfunktion besteht 
(Andersson et al. 1993; Mangos et al. 1995). Es wäre demnach möglich, dass der untersuchte Polymorphismus mit der beschriebenen erhöhten EPO-Konzentration im Blut und/oder eine vorbestehende Niereninsuffizienz einen Einfluss auf den Bedarf einer postoperativen Nierenersatztherapie haben.

Song und Mitarbeiter zeigten in einer kleinen Pilotstudie, dass die prophylaktische Gabe von EPO ein akutes Nierenversagen verhindern kann und die postoperative Nierenfunktion verbessert. Bedenkt man jedoch die Theorie, dass der untersuchte Polymorphismus die Erhöhung der EPO-Konzentration bedingt, und dass EPO mit einem erhöhten Risiko für thrombembolische Ereignisse (Corwin et al. 2007), kardiovaskuläre Komplikationen (Singh et al. 2006) und einer Verminderung der Nierenfunktion (Garcia et al. 1988) assoziiert ist, sind diese Ergebnisse nicht mit denen dieser Studie vereinbar. Es wurden zwar keine Beweise für das Vorliegen einer akuten Nierenschädigung bei den Nierenfunktionsparametern gefunden und auch der RIFLEScore und der ARF-Score zeigten keinen Unterscheid zwischen den verschiedenen Genotypen. Andererseits wäre es aber auch möglich, dass die Beobachtungszeit zu kurz war, als dass ein akutes Nierenversagen in den Laborparametern aufgefallen wäre. Ein Anstieg des postoperativen Serumkreatinins und ein Abfall der postoperativen errechneten glomerulären Filtrationsrate (eGFR) waren fünf Tage postoperativ signifikant, also zu dem Zeitpunkt, zu dem ein akutes Nierenversagen in der Regel auftritt (Song et al. 2009).

Obwohl sich in dieser Studie ein signifikanter Unterschied in der Anwendung einer intraaortalen Ballonpumpe (IABP) postoperativ zwischen den Genotyp-Gruppen zeigte $(p=0,02)$, ist fragwürdig, ob diese Beobachtung einen Einfluss auf das postoperative Outcome in Bezug auf eine Niereninsuffizienz, postoperative Hämodynamik oder eine Katecholamintherapie hat. Die Anwendung einer IABP geht mit einer Verbesserung der Hämodynamik einher, was zu einer vermehrten Perfusion der abdominellen Organe und somit auch der Niere führt. Dies kann sogar einen protektiven Effekt auf ein akutes Nierenversagen haben (Tokunga et al. 2000; Sloth et al 2008; Moro 1992). Vohra und Dimitri konnten im Jahr 2006 sogar belegen, dass die präoperative Anlage einer IABP zu einer Verminderung des Auftretens einer akuten Niereninsuffizienz führt.

Andererseits ist geht die Anwendung einer IABP mit dem Risiko für ischämische Komplikationen einher, die in einer Organschädigung resultieren können. So kann es beim Einführen und Aufblasen des Ballonkatheters bei Vorliegen einer 
Atherosklerose zu einer Plaqueruptur kommen. So entstandene Beinischämien sind als die häufigste Komplikation einer IABP-Anwendung in der Literatur beschrieben (Baskett et al. 2002; Assis et al 2009). Kommt es zu einer Plaqueruptur in der thorakalen Aorta oberhalb des Abgangs der Nierenarterie, kann eine Nierenarterienembolie als Komplikation auftreten. Ein solches Ereignis ist folglich mit einer schlechteren Nierenperfusion assoziiert und vermindert die Nierenfunktion.

Auch Blanloeil et al. beschrieben schon im Jahr 1985, dass die Anwendung einer IABP mit dem vermehrten Auftreten eines akuten Nierenversagens assoziiert ist (Blanloeil et al. 1985). Ursächlich sahen sie die zumeist deutlich verschlechterte Hämodynamik und somit auch Nierenperfusion der Patienten, die den Einsatz einer IABP benötigen. Ahmadi et al. beschreiben in ihrer Studie von 2009 sogar die Anwendung einer IABP als den wichtigsten Prädiktor eines postoperativen akuten Nierenversagens. Auch ihrer Beobachtung liegt zugrunde, dass die Verminderung der postoperativen Nierenfunktion mit einem geringeren kardialen Auswurf assoziiert ist, was den vermehrten Bedarf einer IABP- Anwendung zur Folge hat.

Die Auswirkungen einer IABP-Anwendung auf die postoperative Nierenfunktion sind also fraglich und in der Literatur bereits kontrovers diskutiert worden. In dieser Studie zeigte sich in der univariaten Analyse eine signifikant vermehrte Anwendung der IABP in der TT-Risikogruppe, bei der auch die Anwendung einer CVVH signifikant häufiger auftrat. Dennoch ist ein kausaler Zusammenhang weiterhin fraglich, zumal in der multivariaten Analyse nachgewiesen wurde, dass die Anwendung einer IABP nicht als unabhängiger Risikofaktor zu sehen ist.

Die Pathophysiologie einer renalen Minderfunktion nach Herzoperation ist komplex und bisher wenig verstanden. In der Konsequenz ist es wichtig, dass Kliniker und Forscher weiterhin die postoperative Nierenfunktion bei Patienten beobachten und in neuen Studien untersuchen, um weitere Erkenntnisse $\mathrm{zu}$ gewinnen. In diesem Zusammenhang werden genetische Assoziationen immer wichtiger und interessanter, insbesondere wenn sie in Kombination mit anderen, bekannten Risikofaktoren untersucht werden. Der Schlüssel ist es, diejenigen Patienten mit dem höchsten Risiko einer Komplikation $\mathrm{zu}$ identifizieren und schon im Voraus eine angemessene, intensivierte Therapie entsprechend $\mathrm{zu}$ planen. Unter Berücksichtigung der Pathophysiologie, die hinter den beobachteten klinischen Zuständen steckt, offenbaren sich einige häufige Merkmale, die einen Hinweis darauf geben können, welche Patienten möglicherweise Komplikationen entwickeln werden und welche nicht. Des 
Weiteren können solche Studien eine Hilfe darstellen, wenn es darum geht, ein präoperatives Risikoprofil zu erstellen und mögliche zusätzliche Ansatzpunkte einer gezielten protektiven Therapie zu identifizieren.

Bei der Interpretation dieser Studie ist es wichtig, einige bedeutende Einschränkungen $\mathrm{zu}$ berücksichtigen. Zum einen wurde die postoperative Nierenfunktion mithilfe der Cockcroft-Gault-Formel berechnet, welche Serumkreatinin und das Körpergewicht (als ein Maß der Muskelmasse) mit einbezieht, um die Nierenfunktion nach der Operation einzuschätzen. Während des postoperativen Zeitraums könnten diese Berechnungen aufgrund des Ungleichgewichts zwischen der Kreatininproduktion und -ausscheidung, welche durch die unterschiedlichsten Faktoren bedingt sein kann, nicht exakt genug sein. Dazu gehört eine Veränderung der Nierenfunktion als Anpassungsreaktion auf die Operation, eine Abnahme der Muskelmasse oder Schädigung des Muskels im Rahmen der Operation und postoperativen Bewegungsmangels, eine Leberdysfunktion und zahlreiche unterschiedliche Medikamente. Des Weiteren war die postoperative Beobachtungszeit auf die ersten 24 Stunden auf der Intensivstation begrenzt. Folglich wurden Komplikationen, die nach der Verlegung von der Intensivstation auftraten, in dieser Studie nicht erfasst. Ferner ist es als problematisch anzusehen, dass in dieser Studie keine Messung von EPO im Blut vorgenommen wurde. Zwar belegten Tong et al. 2008 in ihrer Studie, dass der TT-Genotyp mit einer erhöhten EPO-Konzentration im Blut einhergeht, dieses Phänomen wurde allerdings nicht eigens in dieser Studie nochmal bestätigt. Es wurde also die Aussage von Tong et al. dieser Studie zugrunde gelegt und auf eine entsprechende eigene Datenerhebung verzichtet. Eine weitere Einschränkung resultiert aus der Tatsache, dass diese Studie nicht auf den operativen Eingriff eines Koronarbypasses oder eines Klappenersatzes beschränkt war. Die Variabilität in den vorgenommenen Eingriffen könnte die Studienergebnisse beeinflusst haben.

Letztendlich war auch die in dieser Studie untersuchte Population limitiert. Alle untersuchten Patienten waren Kaukasier und repräsentierten somit nur einen Bruchteil der Patienten, die sich einer Herzoperation mit HLM unterziehen - in einem einzigen Zentrum. Folglich könnten diese Ergebnisse nicht unbedingt für die gesamte Population gelten. Es handelt sich außerdem um vorerkrankte Patienten mit einer so schwerwiegenden Erkrankung, die einer Herzoperation bedurfte. Es hat also eine gewisse Vorselektion bei dem Patientenkollektiv bestanden, sodass man nicht von einer komplett randomisierten Studienpopulation ausgehen kann. 
Aufgrund der relativ kleinen Anzahl untersuchter Patienten in den Gruppen ist auch die Aussagekraft dieser Studie zu relativieren. Es ist also notwendig, dass die beobachteten Ergebnisse in weiteren Studien mit möglichst wenigen der hier bestehenden Einschränkungen untersucht werden, um $\mathrm{zu}$ bestätigen, ob eine Homozygotie für TT im EPO-SNP-rs1617640-Promotor-Polymorphismus tatsächlich den beschriebenen Einfluss auf eine postoperative Niereninsuffizienz mit Dialysepflichtigkeit nach einer Herzoperation mit HLM hat.

Zusammenfassend lässt sich sagen, dass die vorliegende Studie einen Zusammenhang zwischen dem SNP-rs1617640 Polymorphismus im Promotorgen von EPO und dem Auftreten eines Nierenversagens nach Herzoperation nahelegt. Sie unterstützt die Hypothese, dass Patienten, die homozygote TT-Allelträger des EPOSNP-rs1617640 sind, einem erhöhten Risiko ausgesetzt sind, ein postoperatives Nierenversagen zu entwickeln. Aufgrund der möglicherweise begrenzten Aussagekraft dieser Studie, die auf der relativ geringen Probandenzahl basiert, wäre es wünschenswert, diese Hypothese in weiteren, größeren Studien zu untersuchen, um mit deren Hilfe noch weiterreichende Ergebnisse präsentieren zu können. 


\section{$5 \quad$ Zusammenfassung}

Eine Schädigung der Niere im Anschluss an eine HLM-gekoppelte Herzoperation ist eine der ernsthaftesten und gefährlichsten Komplikationen in diesem Zusammenhang. Die Ursachen für das Auftreten eines solchen Nierenversagens sind bisher nur wenig erforscht und verstanden. In der vorliegenden Studie wurde der Zusammenhang zwischen dem SNP-rs1617640-Polymorphismus im Promotorgen von EPO und des Auftretens sowie der Schwere einer Niereninsuffizienz in Folge einer Herzoperation mit Anschluss an die Herz-Lungen-Maschine untersucht.

Dafür wurden 481 Patienten, die sich einer Herzoperation unterziehen mussten, untersucht. Der SNP-rs1617640-Polymorphismus wurde mithilfe einer Real-Time-PCR bestimmt und die Patienten anhand ihres Genotyps in 3 Gruppen eingeteilt (homozygote T- Allelträger (TT), heterozygote TG-Allelträger oder homozygote G-Allelträger (GG)).

Bezüglich der präoperativen Risikofaktoren zeigte sich kein signifikanter Unterschied zwischen den Gruppen, mit Ausnahme einer vorbestehenden renalen Dysfunktion, die bei TT-Genträgern häufiger war. Ein Unterschied bei präoperativ verordneten Medikamenten zeigte sich nur bei Antiarrhythmika, deren Anwendung bei TT-Allelträgern vermehrt war. Perioperativ fiel auf, dass in der Gruppe der TTAllelträger mehr Individuen eine Nierenersatztherapie nach der Operation benötigten als in den anderen Gruppen. Die Nierenfunktionsparameter hingegen unterschieden sich nicht signifikant in Bezug auf die Gruppen. Außerdem war bei den TT-Allelträgern ein signifikanter Anstieg der S-CPK-MB zu verzeichnen sowie eine vermehrte Anwendung einer IABP.

Die Mortalitätsrate betrug 8,3\% unter allen Patienten und unterschied sich nicht signifikant bezüglich der Gruppen.

Zusammenfassend lässt sich sagen, dass diese Studie die Hypothese unterstützt, dass der SNP-rs1617640-Polymorphismus im Promotorgen von EPO einen Einfluss auf das Auftreten eines Nierenversagens nach Herzoperation hat, welches eine Nierenersatztherapie benötigt. Diese Tendenz sollte jedoch noch durch weitere größere Studien bestätigt werden. 


\section{Literaturverzeichnis}

Ahmadi H, Karimi A, Davoodi S, Movahedi N, Marzban M, Abbasi K, Salehi Omran A, Shirzad M, Abbasi SH, Tazik M (2009): Determinant factors of renal failure after coronary artery bypass grafting with on-pump technique. Med Princ Pract $\underline{18}, 300-304$

Anagnostou A, Lee ES, Kessimian N, Levinson R, Steiner M (1990): Erythropoietin has a mitogenic and positive chemotactic effect on endothelial cells. Proc Natl Acad Sci $\underline{87}, 5978-5982$

Anagnostou A, Liu Z, Steiner M, Chin K, Lee ES, Kessimian N, Noguchi CT (1994): Erythropoietin receptor mRNA expression in human endothelial cells. Proc Natl Acad Sci US 91, 3974-3978

Anderson RJ, O'Brien M, MaWhinney S, VillaNueva CB, Moritz TE, Sethi GK, Henderson WG, Hammermeister KE, Grover FL, Shroyer AL (1999): Renal failure predisposes patients to adverse outcome after coronary artery bypass surgery. VA Cooperative Study no. 5. Kidney Int 55, 1057-1062

Anderson RJ, O'Brien M, MaWhinney S, VillaNueva CB, Moritz TE, Sethi GK, Henderson WG, Hammermeister KE, Grover FL, Shroyer AL (2000): Mild renal failure is associated with adverse outcome after cardiac valve surgery. Am J Kidney Dis $\underline{35}, 1127-1134$

Andersson LG, Ekroth R, Bratteby LE, Hallhagen S, Wesslén O (1993): Acute renal failure after coronary surgery - a study of incidence and risk factors in 2009 consecutive patients. Thorac Cardiovasc Surg $\underline{41}, 237-241$

Antunes P, Prieto D, Ferrao de Oliveira J, Antunes M (2004): Renal dysfunction after myocardial revascularization. Eur J Cardiothorac Surg 25, 597-604

Assis RB, Azzolin K, Boaz M, Rabelo ER (2009): Complications of intra-aortic balloon in a cohort of hospitalized patients: implications for nursing care. Rev Lat Am Enfermagem 17, 658-663

Bachmann S, Le Hir M, Eckehardt K (1993): Co-localization of erythropoietin m-RNA and ecto-5-nucleotidase immunoreactivity in peritubular cells of rat renal cortex indicates that fibroblasts produce erythropoietin. J Histochem Cytochem $\underline{41}$, 335-341

Bahlmann FH, Song R, Boehm SM, Mengel M, von Wasielewski R, Lindschau C, Kirsch T, de Groot K, Laudeley R, Niemczyk E (2004): Low-dose therapy with the long-acting erythropoietin analogue darbepoetin alpha persistently activates endothelial Akt and attenuates progressive organ failure. Circulation $\underline{110}$, 10061012 
Baskett RJ, Ghali WA, Maitland A, Hirsch GM (2002): The Intraaortic Balloon Pump in Cardiac Surgery. Ann Thorac Surg 74,1276-1287

Blanloeil Y, Train M, Vincent C, Meilhan E, Levrel A, Michaud JL, Dupon H, Duveau D, Dixneuf B (1985): Acute renal failure after extracorporeal circulation with aortic counterpulsation in surgically treated patients. Ann Fr Anesth Reanim $\underline{4}$, 283-288

Bondurant MC, Koury MJ (1986): Anemia induces accumulation of erythropoietin mRNA in the kidney and liver. Mol Cell Biol $\underline{6}, 2731-2733$

Buselmaier W, Tariverdian G: Humangenetik, 4. Auflage; Springer Medizin Verlag, Heidelberg 2007,4-21, 64-76

Carlini RG, Reyes A, Rothstein M (1995): Recombinant human erythropoietin stimulates angiogenesis in vitro. Kidney Int $\underline{47}, 740-745$

Chertow GM, Lazarus JM, Christiansen CL, Cook EF, Hammermeister KE, Grover F, Daley J (1997): Preoperative renal risk stratification. Circulation 95, 878-884

Chertow GM, Levy EM, Hammermeister KE, Grover F, Daley J (1998): Independent association between acute renal failure and mortality following cardiac surgery. Am J Med 104, 343-348

Chew ST, Newman MF, White WD, Conlon PJ, Saunders AM, Strittmatter WJ, Landolfo K, Grocott HP Stafford-Smith M (2000): Preliminary report on the association of apolipoprotein E polymorphisms, with postoperative peak serum creatinine concentrations in cardiac surgical patients. Anesthesiology $\underline{93}, 325-$ 331

Chong ZZ, Kang JQ, Maiese K (2002): Angiogenesis and plasticity: role of erythropoietin in vascular systems. J Hematother Stem Cell Res $\underline{11}, 863-871$

Colombo MG, Paradossi U, Andreassi MG, Botto N, Manfredi S, Masetti S, Biagini A, Clerico A (2003): Endothelial nitric oxide synthase gene polymorphisms and risk of coronary artery disease. Clin Chem $\underline{49}, 389-95$

Conlon PJ, Stafford-Smith M, White WD, Newman MF, King S, Winn MP Landolfo K (1999): Acute renal failure following cardiac surgery. Nephrol Dial Transplant $\underline{14}, 1158-1162$

Corwin HL, Gettinger A, Fabian TC, May A, Pearl RG, Heard S, An R, Bowers PJ, Burton P, Klausner MA (2007): Efficacy and safety of epoetin alfa in critically ill patients. N Engl J Med 357, 965-976

DaSilva J, Lacombe C, Bruneval P, Casadevall N, Leporrier M, Camillieri J, Bariety J, Tambourin P, Varet B (1990): Tumor cells are the site of erythropoietin synthesis in human renal cancers associated with polycythemia. Blood $\underline{75}$, 577-582 
Davila-Roman VG, Kouchoukos NT, Schechtman KB, Barzilai B (1999):

Atherosclerosis of the ascending aorta is a predictor of renal dysfunction after cardiac operations. J Thorac Cardiovasc Surg 117, 111-116

Digicaylioglu M, Bichet S, Marti HH, Wenger RH, Rivas LA, Bauer C, Gassmann M (1995): Localization of specific erythropoietin binding sites in defined areas of the mouse brain. Proc Natl Acad Sci USA 92, 371-372

Diskin CJ, Stokes TJ, Dansby LM, Radcliff L, Carter TB (2007): A hypothesis: Can erythropoietin administration affect the severity of retinopathy in diabetic patients with renal failure? Am J Med Sci 334, 260-264

Doggrell SA (2002): The therapeutic potential of dopamine modulators on the cardiovascular and renal systems. Expert Opin Investig Drugs 11, 631-644

Endre ZH (1997): Post cardiac surgery acute renal failure in the 1990s. Aust NZ J Med $\underline{25}, 278-279$

Estler CJ: Pharmakologie und Toxikologie; Schattauer Verlag Stuttgart, New York 1999, 364

Garcia DL, Anderson S, Rennke HG, Brenner BM (1988): Anemia lessens and its prevention with recombinant human erythropoietin worsens glomerular injury and hypertension in rats with reduced renal mass. Proc Natl Acad Sci USA $\underline{85}$, 6142- 6146

Genc S, Koroglu TF, Genc K (2004): Erythropoietin as a novel neuroprotectant. Res Neurol Neurosci 22, 105-119

Haase-Fielitz A, Haase M, Bellomo R Dragun D (2007): Genetic polymorphisms in sepsis- and cardiopulmonary bypass-associated acute kidney injury. Contrib Nephrol 156, 75-91

Heeschen C, Aicher A, Lehmann R, Fichtlscherer S, Vasa M, Urbich C, Muildner-Rihm C, Martin H, Zeiher AM, Dimmeler S (2003): Erythropoietin is a potent physiologic stimulus for endothelial progenitor cell mobilization. Blood $\underline{102}$, $1340-1346$

Hosaka S, Kamiya K, Akimoto S, Suzuki O, Kobayashi M, Matsukawa T, Tada Y (1994): Atheromatous embolization as a cause of postoperative renal dysfunction in infrarenal aortic reconstructive surgery. Nippon Geka Gakkai Zasshi 95, 109-115

Huang L, Bunn H (1995): Regulation of the erythropoietin gene expression. Curr Opin Hematology 2 , 125-131

Ibelgaufts H: Lexikon Zytokine; Medikon Verlag München 1992, 83-86

Isbir SC, Tekeli A, Ergen A, Yilmaz H, Ak K, Civelek A, Zeybek U Arsan S (2007):

Genetic polymorphisms contribute to acute kidney injury after coronary artery bypass grafting. Heart Surg Forum 10, E439-444 
Ishikawa A, Suzuki K, Fujita K (1999): A preventive effect of a selective endothelin-A receptor antagonist, S-0139, on the erythropoietin-induced reduction of the renal cortical blood flow. Urol Res 27, 312-314

Jaquet K, Krause K, Tawakol-Khodai M, Geidel S, Kuck KH (2002): Erythropoietin and VEGF exhibit equal angiogenic potential. Microvasc Res $\underline{64}, 326-333$

Jeffreys R, Napier J, Reynolds S (1982): Erythropoietin levels in the posterior fossa haemangioblastoma. J Neurol Neurosurg Psychiatry 4, 264-266

Jelkmann W (1994): Biology of erythropoietin. Clin Investig $\underline{72}, 3-10$

Jelkmann W, Metzen E (1996): Erythropoietin in the control of red cell production. Ann Anat $\underline{178}, 391-403$

Juul SE (2000): Nonerythropoietic roles of erythropoietin in the fetus and neonate. Neonat Haematol 27, 527-541

Juul SE, Yachnis AT, Christensen RD (1998): Tissue distribution of erythropoietin and erythropoietin receptor in the developing human fetus. Early Hum Dev $\underline{52}, 235-$ 249

Karadag R, Yagci R, Aydin B, Kanbay M, Erdurmus M, Keskin UC, Akcay A, Durmus $M$ (2009): Effects of erytropoietin treatment and hemodialysis on the serum endothelin level and intraocular pressure of hemodialysis patients. Int Ophthalmol 29, 385-388

Koury MJ, Bondurant MC (1990): Erythropoietin retards DNA breakdown and prevents programmed cell death in erythroid progenitor cells. Science $\underline{248}, 378-381$

Koury ST, Bondurant MC, Koury MJ (1988): Localization of erythropoietin synthesizing cells in murine kidneys by in situ hybridization. Blood $\underline{71}, 524-527$

Maiese K, Li F, Chong ZZ (2005): New avenues of exploration for erythropoietin. JAMA 293, 90-95

Mangano CM, Diamondstone LS, Ramsay JG, Aggarwal A, Herskowitz A Mangano DT (1998): Renal dysfunction after myocardial revascularization: risk factors, adverse outcomes, and hospital resource utilization. The Multicenter Study of Perioperative Ischemia Research Group. Ann Intern Med 128, 194-203

Mangos GJ, Brown MA, Chan WY, Horton D, Trew P, Whitworth JA (1995): Acute renal failure following cardiac surgery: incidence, outcomes and risk factors. Aust N Z J Med 25, 284-289

Martinez-Pellus AE, Merino P, Bru M, Canovas J, Seller G, Sapina J, Fuentes T Moro J (1997): Endogenous endotoxemia of intestinal origin during cardiopulmonary bypass. Role of type of flow and protective effect of selective digestive decontamination. Intensive Care Med 23, 1251-1257 
Maxwell A, Lappin T, Johnston C, Bridges J, McGeowin M (1990): Erythropoietin production in kidney tubular cells. Br J Hemato $\underline{74}$, 535-539

Moro H (1992): Clinical and experimental study of the production of renal hemodynamic effects of IABP-assisted pulsatile flow extracorporeal circulation. Nippon Kyobu Geka Gakkai Zasshi 무, 51-60

Nypaver TJ, Shepard AD, Reddy DJ, Elliott JP Jr, Ernst CB (1993): Supraceliac aortic cross-clamping: Determinants of outcome in elective abdominal aortic reconstruction. J Vasc Surg 17, 868-875

Okabe T, Urabe A, Kato T, Chiba S, Takatu F (1985): Production of erythropoietin-like activity by human renal and hepatic carcinomas in cell culture. Cancer 55, 19181923

Parsa CJ, Kim J, Riel RU, Pascal LS, Thompson RB, Petrofski JA, Matsumoto A, Stamler JS, Koch WJ (2004): Cardioprotective effects of erythropoietin in the reperfused ischemic heart: a potential role for cardiac fibroblasts. J Biol Chem $\underline{279}, 20655-20662$

Pinto-Sietsma SJ, Herrmann SM, Schmidt-Petersen K, Niu T, Hillege HL, Janssen WM, de Zeeuw D, de Jong P, Kreutz R (2003): Role of the endothelin-1 gene locus for renal impairment in the general nondiabetic population. J Am Soc Nephrol $\underline{14}, 2596-602$

Popov AF, Hinz J, Liakopoulos OJ, Schmitto JD, Seipelt R, Quintel M, Schoendube FA (2008): Influence of angiotensin-I-converting-enzyme insertion/deletion gene polymorphism on perioperative hemodyamics after coronary bypass graft surgery. J Cardiovasc Surg $\underline{49}$, 255-260

Popov AF, Hinz J, Schulz EG, Schmitto JD, Wiese CH, Quintel M, Seipelt R, Schoendube FA (2009): The eNOS 786C/T polymorphism in cardiac surgical patients with cardiopulmonary bypass is associated with renal dysfunction. Eur J Cardiothorac Surg 36, 651-656

Porter DL, Goldberg MA (1993): Regulation of Erythropoietin production. Exp Hematol 21, 399-404

Pugh C, Tan C, Jones R, Ratcliff P (1991): Functional analysis of an oxygen-regulated transcriptional enhancer lying 3 'to the mouse erythropoietin gene. Proc Natl Acad Sci USA $\underline{88}, 10553-10557$

Rao V, Weisel RD, Buth KJ, Cohen G, Borger MA, Shiono N, Bhatnagar G, Fremes SE, Goldman BS, Christakis GT (1997): Coronary artery bypass grafting in patients with non-dialysis-dependent renal insufficiency. Circulation $\underline{96}, 38-43$

Renz-Polster H, Krautzig S: Basislehrbuch Innere Medizin, 4. Auflage; Elsevier Verlag, München 2008, 985-989

Ribatti D, Presta M, Vacca A, Ria R, Giuliani R, Dell'Era P, Nico B, Roncali L, 
Dammacco F (1999): Human erythropoietin induces a pro-angiogenic phenotype in cultured endothelial cells and stimulates neovascularization in vivo. Blood $\underline{93}$, $2627-2636$

Roach GW, Kanchuger M, Mangano CM, Newman M, Nussmeier N, Wolman R, Aggarwal A, Marschall K, Graham SH, Ley C (1996): Adverse cerebral outcomes after coronary bypass surgery. Multicenter Study of Perioperative Ischemia Research Group and the Ischemia Research and Education Foundation Investigators. N Engl J Med 335, 1857-1863

Romanowski R, Sytkowski A (1994): The Molecular Structure of Human Erythropoietin. Hematol Oncol Clin North Am $\underline{8}, 885-894$

Rossi GP, Cesari M, Zanchetta M, Colonna S, Maiolino G, Pedon L, Cavallin M, Maiolino P Pessina AC (2003): The T-786C endothelial nitric oxide synthase genotype is a novel risk factor for coronary artery disease in Caucasian patients of the GENICA study. J Am Coll Cardiol 41, 930-937

Sear JW (2005): Kidney dysfunction in the postoperative period. Br J Anaesth 95, 20-32

Semenza G, Wang G (1992): A nuclear factor induced by hypoxia via de novo protein synthesis binds to the human erythropoietin gene enhancer at a site required for transcriptional activation. Mol Cell Biol 12, 5447-5454

Singh AK, Szczech L, Tang KL, Barnhart H, Sapp S, Wolfson M, Reddan D (2006): Correction of anemia with epoetin alfa in chronic kidney disease. N Engl J Med $\underline{355}, 2085-2098$

Sloth E, Sprogøe P, Lindskov C, Hørlyck A, Solvig J, Jakobsen C (2008): Intra-aortic balloon pumping increases renal blood flow in patients with low left ventricular ejection fraction. Perfusion $\underline{23}$, 223-226

Song YR, Lee T, You SJ, Chin HJ, Chae DW, Lim C, Park KH, Han S, Kim JH, Na KY (2009): Prevention of acute kidney injury by erythropoietin in patients undergoing coronary artery bypass grafting: a pilot study. Am J Nephrol $\underline{30}$, 253-260

Stafford-Smith M, Podgoreanu M, Swaminathan M, Phillips-Bute B, Mathew JP, Hauser EH, Winn MP, Milano C, Nielsen DM, Smith M, et al. (2005): Association of genetic polymorphisms with risk of renal injury after coronary bypass graft surgery. Am J Kidney Dis $\underline{45}, 519-530$

Taniguchi F, de Souza A, Martins A (2007): Cardiopulmonary bypass time as a risk factor for acute renal failure. Braz J Cardiovasc Surg 22, 201-205

Tavian M, Cortes F, Robin C, Schiavon V, Hallais MF, Coulombel L, Charbord P, Labastie MC, Peault B (2000): The hemangioblast, common precursor of endothelial and hematopoietic cells. Transfus Clin Biol ㄱ, 238-241

Tokunaga S, Tominaga R, Nakano T, Fukae K, Takeshita A, Yasui H (2000): Effects of 
intra-aortic ballon pumping on renal sympathetic nerve activity and renal circulation in dogs. J Cardiovasc Surg $\underline{41}, 669-674$

Tong Z, Yang Z, Patel S, Chen H, Gibbs D, Yang X, Hau VS, Kaminoh Y, Harmon J, Pearson E (2008): Promoter polymorphism of the erythropoietin gene in severe diabetic eye and kidney complications. Proc Natl Acad Sci USA $\underline{105}$, 6998-7003

Tonnesen E, Christensen VB Toft P (1996): The role of cytokines in cardiac surgery. Int J Cardiol $\underline{53}, 1-10$

Uchida E, Morimoto K, Kawasaki N, Izaki Y, Abdu Said A, Hayakawa T (1997): Effect of active oxygen radicals on protein and carbohydrate moieties of recombinant human erythropoietin. Free Radic Res 27, 311-323

Vogt C, Pentz S, Rich IN (1989): A role for the macrophage in normal hemopoiesis: III. In vitro and in vivo erythropoietin gene expression in macrophages detected by in situ hybridization. Exp Hematol 17, 391-397

Vohra HA, Dimitri WR (2006): Elective intraaortic balloon counterpulsation in highrisk off-pump coronary artery bypass grafting. J Card Surg $\underline{21}, 1-5$

Watanabe D, Suzuma K, Matsui S, Kurimoto M, Kiryu J, Kita M, Suzuma I, Ohashi H, Ojima T, Murakami T (2005): Erythropoietin as a retinal angiogenic factor in proliferative diabetic retinopathy. N Engl J Med 353, 782-792 


\section{Tabellenverzeichnis}

$\begin{array}{lll}\text { Tab. } 1 & \text { Schweregradeinteilung der Nierenschädigung } & \text { S. } 20\end{array}$

$\begin{array}{lll}\text { Tab. } 2 & \text { Allelverteilung } & \text { S. } 29\end{array}$

$\begin{array}{lll}\text { Tab. } 3 \text { Klinische und demographische Verteilung } & \text { S. } 31\end{array}$

$\begin{array}{lll}\text { Tab. } 4 & \text { Präoperative Medikation } & \text { S. } 32\end{array}$

$\begin{array}{lll}\text { Tab. } 5 & \text { Operationsassoziierte Parameter } & \text { S. } 33\end{array}$

$\begin{array}{lll}\text { Tab. } 6 & \text { Perioperative Parameter: Hämodynamik } & \text { S. } 34\end{array}$

$\begin{array}{lll}\text { Tab. } 7 & \text { Perioperative Parameter: Angewandte Medikamente } & \text { S. } 35\end{array}$

Tab. 8 Perioperative Parameter: Nierenfunktion und Scores S. 36

$\begin{array}{lll}\text { Tab. } 9 & \text { Postoperative Parameter } & \text { S. } 37\end{array}$ 


\section{Danksagung}

An erster Stelle danke ich Herrn PD Dr. med. José Hinz für seine Unterstützung während der Entstehung dieser Arbeit, der sowohl bei der Datenerhebung als auch beim Verfassen der Dissertationsschrift immer ansprechbar und für meine Fragen offen war. Ich bedanke mich für die Bereitstellung des interessanten Themas und der Räumlichkeiten sowie für die Unterstützung durch fachliches Wissen und Korrekturlesen.

Des Weiteren danke ich Dr. med. Aron Popov für seine Betreuung während der gesamten Zeit und seine Unterstützung in allen Belangen, die zur Entstehung dieser Arbeit maßgeblich beigetragen haben.

Ich möchte mich außerdem bei Frau Waldmann-Beushausen für die Einführung in die praktische Durchführung der Labormethoden bedanken sowie für ihre freundliche und herzliche Unterstützung und Kooperation.

Ich bedanke mich bei Herrn Dr. rer. nat. Mladen Tzvetkov und Frau Karoline Jobst für die Einführung in die weiterführenden Labormethoden und ihre Unterstützung im Rahmen der praktischen Durchführung. 


\section{Lebenslauf}

Ich wurde am 08.10.1985 in Braunschweig als zweite Tochter des Lehrers Claus Zimmermann und der Lehrerin Marianne Zimmermann, geb. Meinecke geboren. Im Jahr 1992 wurde ich in die Grundschule Mascheroder Holz im Stadtteil Südstadt von Braunschweig eingeschult und besuchte dort die erste bis vierte Klasse bis zum Sommer 1996. Danach besuchte ich die fünfte und sechste Klasse der Orientierungsstufe Lindenbergsiedlung in Braunschweig. Im Anschluss wechselte ich auf das Gymnasium Martino- Katharineum Braunschweig, welches ich von 1998 bis 2002 und 2003 bis 2005 besuchte. Das Schuljahr 2002/2003 verbrachte ich an der Columbia Falls High School in Montana, USA. Meine Hochschulreife erlangte ich im Juli 2005.

Im Oktober 2005 begann ich das Studium der Humanmedizin an der Georg-AugustUniversität in Göttingen und bestand im September 2007 den ersten Abschnitt der ärztlichen Prüfung.

Im klinischen Abschnitt des Studiums war ich im Rahmen von Famulaturen in der Anästhesie, Pädiatrie, Gynäkologie und Augenheilkunde im Städtischen Klinikum Braunschweig tätig, des Weiteren in der Gynäkologie im MVZ Göttingen und in der Pädiatrie im Seehospiz Norderney.

Die Blockpraktika in den Fächern Innere Medizin, Chirurgie und Gynäkologie absolvierte ich im Universitätsklinikum Göttingen in den Abteilungen Hämatologie/ Onkologie, Unfallchirurgie und im Kreißsaal/ Wochenstation. Das Blockpraktikum der Allgemeinmedizin verbrachte ich in der Praxis Frau Dr. Wehpke in Rosdorf und das Blockpraktikum der Pädiatrie im Reinhard-Nieter-Krankenhaus in Wilhelmshaven.

Im Sommer 2008 begann ich meine Dissertationsarbeit unter der Leitung von PD Dr. J. Hinz in der Abteilung Anaesthesiologie II - Operative Intensivmedizin im Zentrum Anaesthesiologie, Rettungs- und Intensivmedizin. Ich werde mein Studium voraussichtlich nach Absolvieren des Staatsexamens im Herbst 2011 beenden. 